
\title{
$\begin{array}{ll}\text { Research Square } & \begin{array}{l}\text { Preprints are preliminary reports that have not undergone peer review. } \\ \text { They should not be considered conclusive, used to inform clinical practice, } \\ \text { or referenced by the media as validated information. }\end{array}\end{array}$ \\ Design of a Novel Cross Beam Six-Dimensional Force Sensor
}

\section{Chun Zhang}

school of mechanical engineering ,hefei university of technology

\section{Yong Wang ( $\nabla$ simenkouwang@sina.com )}

School of mechanical engineering,hefei university of technology https://orcid.org/0000-0001-53783641

\section{Chunfeng Li}

Hefei University of Technology

Shanshan Hu

Anhui Jianzhu University

Jinhong Zhong

Hefei University of Technology

\section{Original Article}

Keywords: Six-dimensional force sensor, Wheatstone full-bridge circuit, statics analysis, response surface analysis

Posted Date: November 5th, 2020

DOl: https://doi.org/10.21203/rs.3.rs-101793/v1

License: (c) (i) This work is licensed under a Creative Commons Attribution 4.0 International License.

Read Full License 


\title{
Design of a Novel Cross Beam Six-Dimensional Force Sensor
}

\author{
Chun Zhang ${ }^{1,2}$,Yong Wang ${ }^{1,2, *}$, Chunfeng $\mathrm{Li}^{1,2}$, Shanshan $\mathrm{Hu}^{3}$ and Jinhong Zhong ${ }^{4}$ \\ (1.School of Mechanical Engineering, Hefei University of Technology, Hefei 230009, China; \\ 2.Intelligent Interconnected Systems Laboratory of Anhui Province (Hefei University of Technology); \\ 3.School of Mechanical and Electrical Engineering, Anhui Jianzhu University, Hefei 230601, China; \\ 4.School of Management, Hefei University of Technology, Hefei 230009, China;)
}

\begin{abstract}
To measure dynamic forces more accurately, a novel elastomer of a six-dimensional force sensor was proposed. The sensor adopted a new inner ring to replace the center platform of the traditional cross beam sensor. Determined the connection mode of the Wheatstone full-bridge circuit, which could realize theoretical decoupling. Then, the key size parameters of the sensor were analyzed by response surface analysis, and the regression equations between the response value and the key sizes of the elastomer were established, which provided a theoretical basis for the sensor design. The analysis results of the examples in this paper show the sensor has good dynamic performance, with the first-order natural frequency as high as $3196.30 \mathrm{~Hz}$. Designed the size parameters by response surface analysis to improve the sensitivity of each force component, which increased the sensitivity of Fx direction by $\mathbf{2 6 . 0 9 \%}$.
\end{abstract}

Index Terms-Six-dimensional force sensor; Wheatstone full-bridge circuit; statics analysis; response surface analysis.

*Correspondence: simenkouwang@hfut.edu.cn;

\section{INTRODUCTION}

Qensor technology was the foundation of information acquisition, processing and transmission, and the technical basis of "automation in the highest sense" ${ }^{[1]}$. With the continual promotion of the application range of high-speed working robots, the requirements of robot sensing and control technology are getting higher and higher ${ }^{[2]}$. The robot's multidimensional force sensor is usually installed between the robot end-effector and the robot arm, which detected the interactive force between the robot and the environment during the working process. The six-dimensional force sensor can sense the full force information in three-dimensional space, which contains three force components: Fx, Fy, Fz, and three torque components: $\mathrm{Mx}, \mathrm{My}, \mathrm{Mz}$. As a fundamental part to improve robot's working level, it has deep research significance and development prospects.

The core technology of six-dimensional force sensor development is about the design of sensor elastomer, whose structure directly affects the performance of the six-dimensional force sensor ${ }^{[3]}$. With the development of robot technology towards high-speed and high-precision, the problem of dynamic force measurement is more and more prominent. To meet the needs of dynamic force measurement, six-dimensional force sensors should have high sensitivity and low cross-interference in each axial. To adapt to different working environments, experts and scholars have developed a variety of the six-dimensional force sensor elastomer. Among them, the integrated six-dimensional force sensor has higher measurement accuracy, lower inter-dimensional coupling, and a smaller lag, which has attracted the attention of many scholars.

Yuan $\mathrm{C}$ et al. designed a six-dimensional force sensor to detect the force information of the humanoid robot's foot, which was small and had adjustable and independent sensitivity to different force components ${ }^{[4-5]}$. Ge Yu et al. invented an ultrathin six-dimensional force sensor based on the cross beam and double E-type membrane structure, which used to gather the force information about the underwater robot at the wrist [6-7]. Besides, considering the structural symmetry, high sensitivity, small inter-dimensional coupling, and other advantages of the cross beam sensor, more and more scholars have improved it to get a six-dimensional force sensor with better performance ${ }^{[8-11]}$. Song Aiguo et al. designed a fingertip three-dimensional force sensor, which adopted the structure of a cross beam and center straight beam so that it has a high measurement accuracy ${ }^{[12]}$. Sun Yongjun et al. proposed a six-dimensional force sensor with a double-parallel beam, which has the characteristics of high sensitivity and small inter-dimensional coupling [ ${ }^{13]}$. Based on the traditional cross beam sensor, $\mathrm{Hu}$ Shanshan et al. proposed a novel six-dimensional wrist force sensor by setting through holes on each sensitive beam, which has good static and dynamic characteristics ${ }^{[14]}$.

To further enhance the performance of the six-dimensional force sensor, this paper proposes a novel six-dimensional force sensor elastomer based on the research results of 
six-dimensional force sensor proposed by $\mathrm{Hu}$ Shanshan et al

[14]. The sensor adopted a new inner ring, which replaced the traditional central platform of cross beam sensor and improved the dynamic performance of the six-dimensional force sensor. The sensor has high sensitivity by setting through holes on the sensitive beam. We determined the connection mode of the Wheatstone full-bridge circuit, which could achieve theoretical decoupling. Then, the key size parameters of the sensor were analyzed by response surface analysis, and the regression equation between the response value and the key size of the elastomer is established, which provided a theoretical basis for the sensor's size parameters design. And by comparing pre-design and post-design parameters, it is proved that the sensor has excellent static and dynamic performance. Finally, the accuracy of the six - dimensional force was verified by the experiment.

\section{STRAIN GAUGES CONNECTION PRINCIPLES OF THE SENSOR}

\section{A. The structural of elastomer}

The elastomer of the six-dimensional force sensor is shown in Figure 1, including the center platform, circumferential beam, radial beam, and circumferential support. When the external load is applied on the center platform, the circumferential beam and radial beam will produce bending deformation. The strain gauge pasted on the beam is connected into the Wheatstone bridge circuit to measure the strain variable of the beam. Then the signal acquisition system is used to process the relevant signals to obtain the load acting on the sensor.

The center platform and circumferential beam are used as the inner ring, the circumferential support is used as the outer ring, they forming the internal and external ring support structure. The two adjacent circumferential beams are connected by a connecting block to form the novel center platform instead of the center platform of the traditional cross beam sensor. The structure changes the transmission path of force by setting circumferential beams in the center of the platform. Compared with the previous cross beam structure, it has high stiffness and good dynamic performance. The inner end of the radial beam connected with the middle of the circumferential beam, forming a "T" beam. The outer end connected with the circumferential support. Based on the stress concentration principle of the circular hole and the measuring principle of the six-dimensional force sensor, the waist hole is set in the reasonable positions of the circumferential beam and radial beam of the sensor. The stress in the beam is concentrated on the both sides of the hole and improved the sensitivity of the sensor. Two vertical waist holes running through the circumferential beam are set in symmetrical positions, which are processed into the " $\mathrm{H}$ " beam. It enhances the sensitivity and the dynamic performance of the sensor. One end of the radial beam is set with waist holes running through its upper and

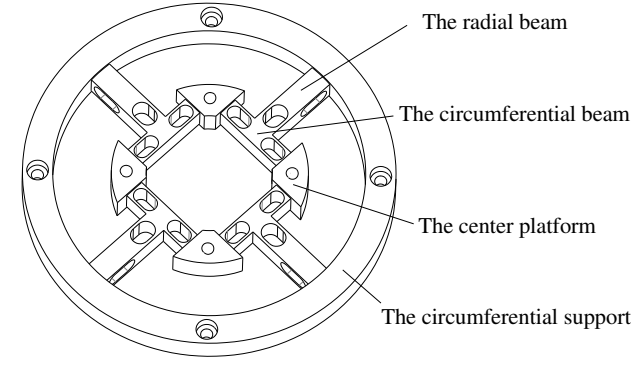

lower surfaces, and the other end is set with waist holes running through its left and right sides. The two ends are processed into a parallel beam, which not only guarantees certain stiffness but also improves the sensitivity of the sensor. Besides, four locating holes are arranged on the connecting block of the center platform and the circumferential support respectively, which facilitates the assembly of elastomer.

Figure 1. The elastic body of the novel cross beam six-dimensional force sensor.

\section{B. Strain gauges position and connection principles of circuits}

To obtain higher resolution and stability of the six-dimensional force sensor, we have to choose the best positions to paste the strain gauges. In this paper, we used the path mapping technique to analyze the relationship between the position of the node and its strain. Under different loads, the strain distribution along the centerline of the corresponding beams' surface is shown in Figure 2. Figure 2(b), 2(c) and 2(d) are discontinuous because of the existence of holes.

According to Figure 2(a), when the force Fx $=50 \mathrm{~N}$ acts on the center platform, the strain distribution inside and outside the circumferential beam is nonlinear. The strain concentrated in the position which closes to the two ends of the holes, and the strain at one end of the hole close to the radial beam is the largest. Considering its structure and sensitivity requirements, the binding position of the inner strain gauges was about $7 \mathrm{~mm}$ away from the ends of the circumferential beam, the outer strain gauges pasted close to the radial beam, which is used for measuring Fx. Similarly, when force $\mathrm{Fz}=50 \mathrm{~N}$ acts on the center platform, the strain gauge is pasted on the radial beam about $2 \mathrm{~mm}$ away from the circumferential support for measuring Fz, as shown in Figure 2(b). When torque $\mathrm{Mx}=$ $2.5 \mathrm{Nm}$ acts on the center platform, the strain gauge is pasted on the radial beam about $6.5 \mathrm{~mm}$ away from the circumferential support for Mx measurement, as shown in Figure 2(c). When torque $\mathrm{Mz}=2.5 \mathrm{Nm}$ acts on the center platform, the strain gauge is pasted on the radial beam about $1.5 \mathrm{~mm}$ away from the circumferential beam to measure Mz, as shown in Figure 2(d). According to the design idea and the analysis of the above simulation results, the strain gauges position of the novel six-dimensional force sensor is showed in Figure 3. 


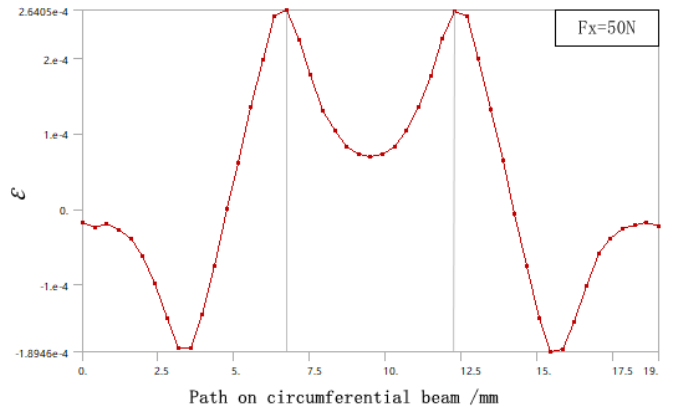

(a)
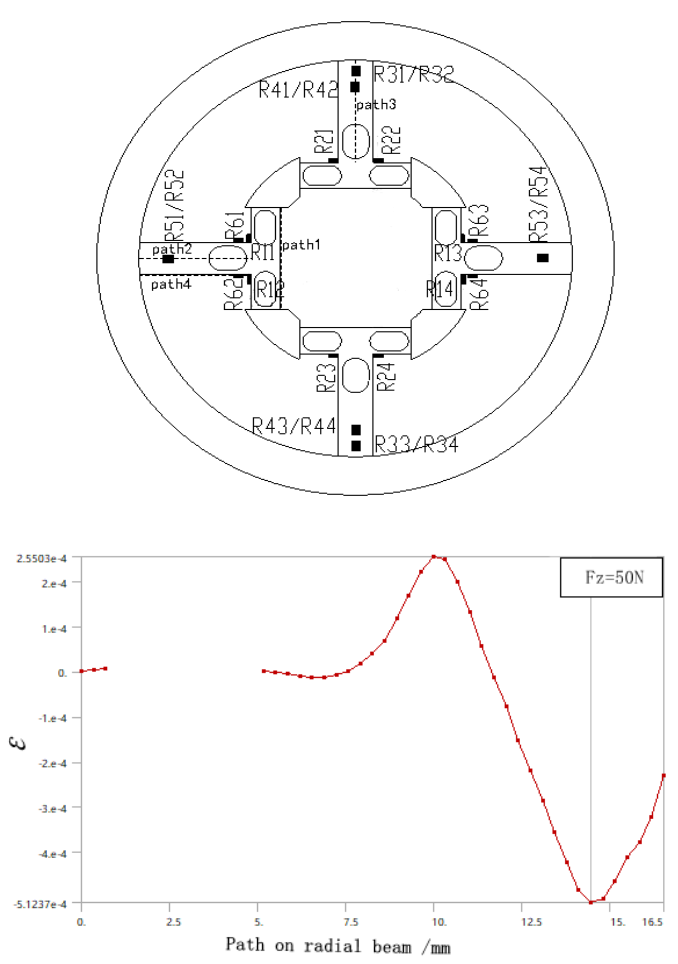

(b)

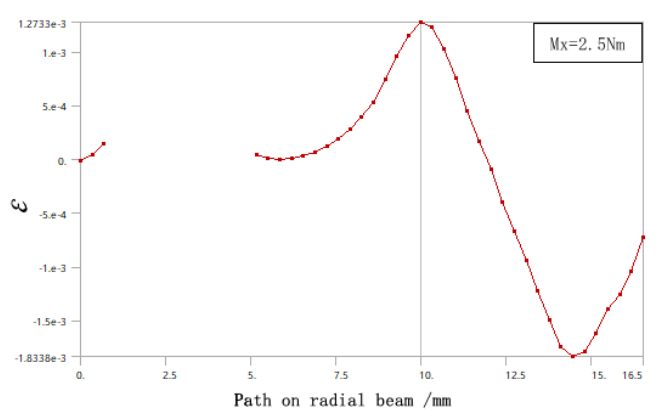

(c)

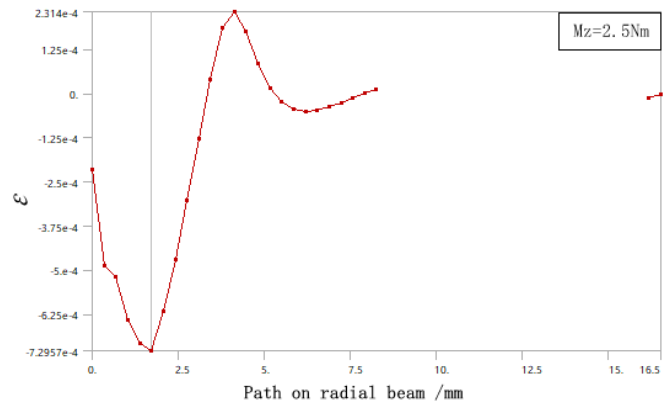

(d)

Figure 2. (a) Strain distribution along the path of the radial beam under $F_{x}=50 \mathrm{~N}$; (b) Strain distribution along the path of the radial beam under $F_{z}=50 \mathrm{~N}$; (c) Strain distribution along the path of the radial beam under $M_{x}=2.5 \mathrm{Nm}$; (d) Strain distribution along the path of radial beam under $M_{z}=2.5 \mathrm{Nm}$.

Figure 3. The strain gauges position of the novel six-dimensional force sensor.

According to simulation results, the strain size and direction of the strain gauge position when loading force or torque. Based on this, we can conclude the connection mode of the Wheatstone full-bridge circuit, as shown in Figure 4. The bridge connection mode can realize the theoretical decoupling.

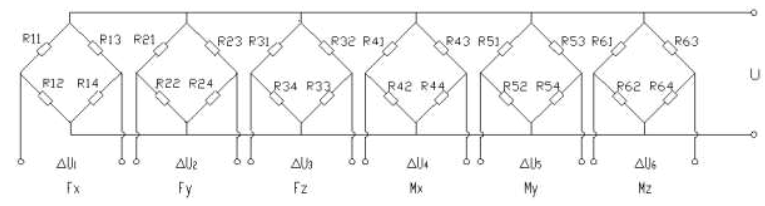


Figure 4. The Wheatstone full-bridge circuit connection mode.

\section{DIMENSION PARAMETERS DESIGN BASED ON RESPONSE SURFACE ANALYSIS}

To obtain better static and dynamic performance of the six-dimensional force sensor, it is necessary to design the key size parameters of the elastomer. Due to the complex structure and various design parameters of the sensor presented in this paper, it is impossible to obtain a precise theoretical analytical expression. So the finite element method (ANSYS) is utilized to the numerical calculation. Considering the workload and design cost, this paper first conducts a preliminary screening of the design parameters by single-factor analysis method and selects the design parameters that have a complex impact on the sensor performance. Then, we used the response surface analysis (RSM) and the finite element method to analyze the size parameters of the elastomer. The Box-Behnken test design is adopted in the test design method.

\section{A. Statics analysis based on the finite element method}

After single-factor analysis, the independent variables are radial beam width $\mathrm{x} 1$, the value range is $[4.00 \mathrm{~mm}, 6.00 \mathrm{~mm}]$. Radial beam height $\mathrm{x}_{2}$, value range: [4.00mm, $6.00 \mathrm{~mm}$; circumferential beam width $\mathrm{x}_{3}$, value range: $[3.50 \mathrm{~mm}$, $5.50 \mathrm{~mm}]$; thickness of transverse hole on radial beam $\mathrm{x}_{4}$, value range: $[0.50 \mathrm{~mm}, 1.00 \mathrm{~mm}]$; thickness of vertical hole on radial beam $\mathrm{x}_{5}$, value range: $[0.50 \mathrm{~mm}, 1.00 \mathrm{~mm}]$; thickness of vertical hole on circumferential beam $\mathrm{x}_{6}$, value range: $[0.40 \mathrm{~mm}$, $0.80 \mathrm{~mm}]$. As the design variables of the Box-Behnken test design, the original design size of the sensor elastomer was selected as the basic size. Response values are the strain measured by the Wheatstone full-bridge circuit under each working conditions and the first-order natural frequency of the elastomer.

Based on the test sites of the Box-Behnken experimental design method provided in response surface analysis software Design-Expert, 54 groups were included ${ }^{[15-17]}$. Combined with the finite element analysis software, we got the response values of each working conditions, the calculation results are showed in Table 1,which can be found in Appendix. Where $\mathrm{y}_{1}, \mathrm{y}_{2}, \mathrm{y}_{3}$, and $\mathrm{y}_{4}$ are respectively the strain measured by the Wheatstone full-bridge circuit under loading $\mathrm{Fx}, \mathrm{Fz}, \mathrm{Mx}$, and $\mathrm{Mz}$. $\mathrm{y}_{5}$ represents the first-order natural frequency of the elastomer, and its unit is Hz. According to material mechanics, the strain has no unit ${ }^{[18-19]}$.

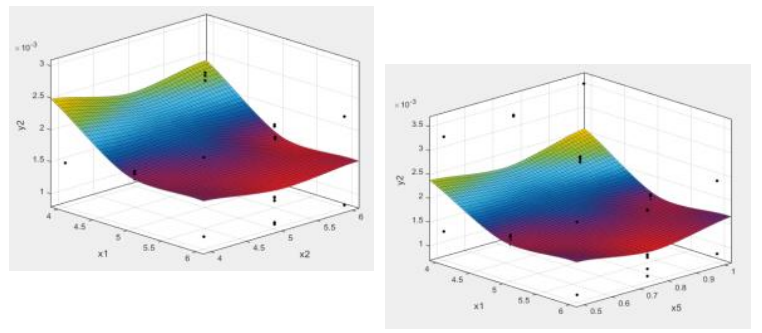

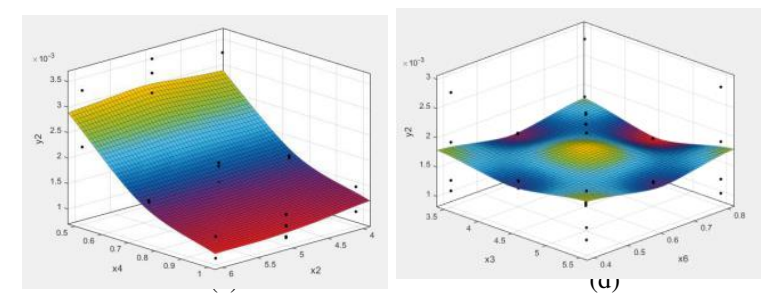

Figure 5. (a) Response surface of $\mathrm{y}_{2}$ vs. $\mathrm{x}_{1}, \mathrm{x}_{2}$; (b) Response surface of $\mathrm{y}_{2}$ vs. $\mathrm{x}_{1}, \mathrm{x}_{5}$; (c) Response surface of $\mathrm{y}_{2}$ vs. $\mathrm{x}_{2}, \mathrm{x}_{4}$; (d) Response surface of $\mathrm{y}_{2}$ vs. $\mathrm{x}_{3}, \mathrm{x}_{6}$.
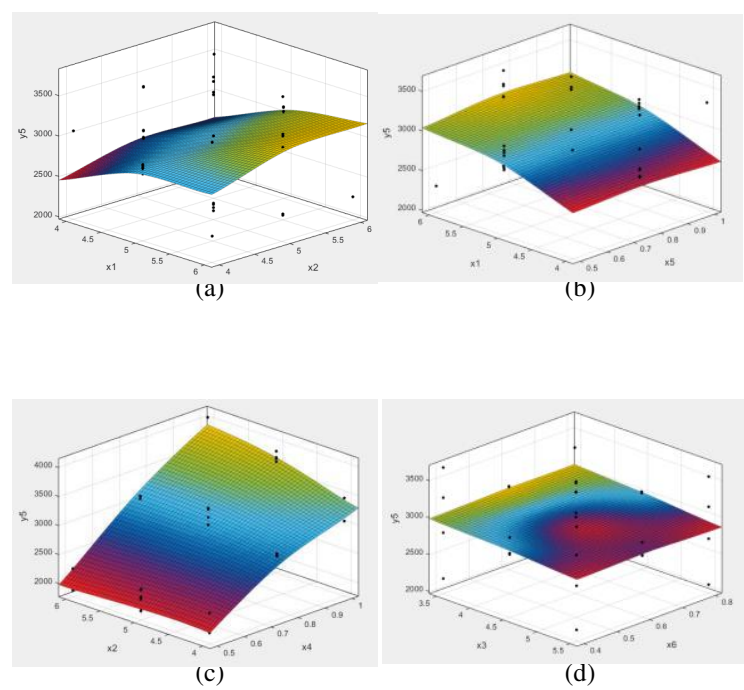

Figure 6. (a) Response surface of $y_{5}$ vs. $x_{1}, x_{2}$; (b) Response surface of $y_{5}$ vs. $x_{1}, x_{5}$; (c) Response surface of $y_{5}$ vs. $x_{2}, x_{4}$; (d) Response surface of $y_{5}$ vs. $x_{3}, x_{6}$.

According to the data in the response surface analysis table, MATLAB is adapted to fit the relevant response surface graph. Where the influences of the radial beams width $\mathrm{x}_{1}$, radial beams height $\mathrm{x}_{2}$, circumferential beams width $\mathrm{x}_{3}$, the thickness of the transverse holes on the radial beam $\mathrm{x}_{4}$, the thickness of the vertical holes on the radial beams $\mathrm{x}_{5}$, and the thickness of the vertical holes on the circumferential beams $\mathrm{x}_{6}$ on the strain $\mathrm{y}_{2}$ measured in the whole bridge circuit and the elastic body first-order natural frequency $\mathrm{y}_{5}$ are showed in Figure 5 and Figure 6 (the black points in the figures are the original data points). Figure 5 and Figure 6 describe the changing trend of the response values caused by the change in the independent variables. These trends can be used to guide the following optimal design. For example, Figure 5(a) shows that to get a larger strain $\mathrm{y}_{2}$, the variables $\mathrm{x}_{1}$ and $\mathrm{x}_{2}$ should be selected with a smaller value while ensuring other need. The same goes for 
everything else.

\section{B. Establish the response surface model}

Owing to the complex structure and numerous design parameters of the sensor elastomer proposed in this paper, we must simplify the sensor model to get the sensor model based on mechanics. However, the six-dimensional force sensor itself is an accurate element. Although the simplified theoretical model has good universality, it can't fully present the mechanical transfer characteristics of the structure. Therefore, the response surface model is adopted in this paper to analyze and design the structure. Through the response surface analysis of the sensor, combined with the evaluation indexes of the response surface model, the expression of the response surface model in each working condition was finally fitted.

(1) Under loading the force Fx, the expression of the response surface model is showed in the equation 3-1:

$$
\begin{aligned}
y_{1}= & 10^{-6} \times\left(32928.00-4220.88 x_{1}-18.95 x_{2}-7367.11 x_{3}\right. \\
& -5943.86 x_{4}-2943.85 x_{5}-28193.00 x_{6} \\
& +1292.70 x_{1} x_{3}-139.61 x_{1} x_{5}+2644.40 x_{1} x_{6} \\
& +2624.90 x_{3} x_{6}+8041.55 x_{4} x_{6}+7974.87 x_{5} x_{6} \\
& +579.98 x_{3}^{2}+3518.82 x_{4}{ }^{2}+4054.06 x_{6}{ }^{2} \\
& -424.55 x_{1} x_{3} x_{6}-67.74 x_{2} x_{5} x_{6}+3.91 x_{1}^{2} x_{3} \\
& -1.41 x_{1}^{2} x_{4}-108.42 x_{1} x_{3}^{2}-4786.48 x_{4}{ }^{2} x_{6} \\
& \left.-4279.13 x_{5} x_{6}{ }^{2}\right)
\end{aligned}
$$

The correlation coefficient of the regression equation $\mathrm{R}^{2}=$ 0.9938 , the correction coefficient $R_{\text {Adj }}=0.9894$, RPred $=$ 0.9447, $\mathrm{R}_{\text {Adj }}$ and $\mathrm{R}_{\text {Pred }}$ are close. The measurement signal-to-noise ratio of the response surface model is required to be greater than 4 , which is 68.848 . It shows that was an accurate model, which can be used to guide the following design.

Under loading the force $\mathrm{Fz}$, the expression of the response surface model is showed in the equation 3-2:

$$
\begin{aligned}
y_{2}= & 10^{-6} \times\left(8448.57-352.02 x_{1}+582.01 x_{2}-300.27 x_{3}\right. \\
& -6071.68 x_{4}-95.47 x_{6}-1.03 x_{1} x_{4}-11.98 x_{1} x_{5} \\
& +15.32 x_{2} x_{3}-1725.09 x_{2} x_{4}-77.29 x_{3} x_{4} \\
& -1687.34 x_{4} x_{5}-407.40 x_{4} x_{6}+2.24 x_{1}^{2}+28.95 x_{3}^{2} \\
& +6466.32 x_{4}^{2}+775.95 x_{5}^{2}+146.24 x_{1} x_{2} x_{4} \\
& +241.91 x_{1} x_{4} x_{5}+18.66 x_{3} x_{4} x_{6}+73.23 x_{1}^{2} x_{4} \\
& -26.79 x_{1}^{2} x_{5}-11.34 x_{1} x_{2}^{2}+0.55 x_{1} x_{3}^{2} \\
& \left.+80.73 x_{2}^{2} x_{4}+0.53 x_{2}^{2} x_{6}\right)
\end{aligned}
$$

The correlation coefficient of the regression equation $R^{2}=$ 0.9997 , the correction coefficient $R_{\text {Adj }}=0.9993$, RPred $=$ 0.9959, $\mathrm{R}_{\mathrm{Adj}}$ and $\mathrm{R}_{\text {Pred }}$ are close. The measurement signal-to-noise ratio is required to be greater than 4 , which is 228.964. It shows that was an accurate model, which can be used to guide the following design.

Under loading the torque $\mathrm{Mx}$, the expression of the response surface model is showed in the equation 3-3:

$$
\begin{aligned}
y_{3}= & 10^{-6} \times\left(67173.00-15534.00 x_{1}-7380.18 x_{2}-0.06 x_{4}\right. \\
& +1964.98 x_{1} x_{2}+7994.43 x_{1} x_{4}-447.72 x_{1} x_{5} \\
& -418.09 x_{2} x_{5}+267.44 x_{3} x_{4}-70.12 x_{3} x_{5}-7.44 x_{3} x_{6} \\
& +5131.62 x_{4} x_{5}+847.23 x_{4} x_{6}+1063.41 x_{1}{ }^{2}+943.51 x_{2}{ }^{2} \\
& -36.51 x_{3}{ }^{2}+0.016 x_{4}^{2}+1662.28 x_{5}^{2}+491.14 x_{1} x_{2} x_{4} \\
& -3.76 x_{1} x_{3} x_{6}-1326.52 x_{1} x_{4} x_{5}+208.47 x_{2} x_{5} x_{6} \\
& -75.79 x_{1} x_{2}-690.21 x_{1}^{2} x_{4}+123.65 x_{1}^{2} x_{5} \\
& -182.735 x_{1} x_{2}{ }^{2}+4.50184 x_{1} x_{3}{ }^{2}-234.487 x_{2}{ }^{2} x_{4} \\
& \left.-15.4026 x_{3}{ }^{2} x_{6}+41.3684 x_{3} x_{6}{ }^{2}-871.963 x_{5} x_{6}{ }^{2}\right)
\end{aligned}
$$


The correlation coefficient of the regression equation $\mathrm{R}^{2}=$ 0.9997 , the correction coefficient $R_{\text {Adj }}=0.9993$, $R_{\text {Pred }}=0.9933$, RAdj and $R_{\text {Pred }}$ are close. The measurement signal-to-noise ratio is required to be greater than 4 , and here is 216.687 . It shows that was an accurate model, which can be used to guide the following design.

Under loading the torque $\mathrm{Mz}$, the expression of the response surface model is showed in the equation 3-4:

$$
\begin{aligned}
y_{4}= & 10^{-6} \times\left(14015.00-363.17 x_{1}+1703.57 x_{2}-1097.77 x_{3}\right. \\
& -15626.00 x_{5}-2008.26 x_{1} x_{5}+3089.13 x_{2} x_{5}-5439.78 x_{2} x_{6} \\
& +12599.00 x_{5} x_{6}+111.76 x_{1}^{2}-617.38 x_{2}^{2}+106.68 x_{3}^{2} \\
& +462.58 x_{5}^{2}+15196.00 x_{6}^{2}-3183.04 x_{2} x_{5} x_{6}+0.29 x_{1}^{2} x_{2} \\
& \left.+1050.28 x_{1} x_{5}^{2}+1278.59 x_{2}^{2} x_{6}-3425.66 x_{2} x_{6}^{2}+9.81 x_{3}^{2} x_{5}\right)
\end{aligned}
$$

The correlation coefficient of the regression equation $R^{2}$ $=0.9921$, correction coefficient $R_{\text {Adj }}=0.9877, R_{\text {Pred }}=0.8319$, $\mathrm{R}_{\text {Adj }}$ and $\mathrm{R}_{\text {Pred }}$ are close. The measurement signal-to-noise ratio is required to be greater than 4 , which is 61.742 . It shows that was an accurate model, which can be used to guide the following design.

The response surface model expression of the first-order natural frequency is showed in the equation 3-5:

$$
\begin{aligned}
y_{5}= & -1139.19+283.82 x_{1}+149.30 x_{2}+100.29 x_{3} \\
& +2872.67 x 4+23.31 x_{1} x_{2}-14.91 x_{1} x_{3}+107.90 x_{1} x_{4} \\
& +555.75 x_{2} x_{4}-64.38 x_{2} x_{6}-111.95 x_{3} x_{4} \\
& +34.23 x_{4} x_{5}+442.84 x_{4} x_{6}-19.89 x_{1}^{2}-54.64 x_{2}^{2} \\
& -2043.91 x_{4}^{2}
\end{aligned}
$$

The correlation coefficient of the regression equation $\mathrm{R}^{2}$ $=0.9989$, the correction coefficient $R_{\text {Adj }}=0.9984, R_{\text {Pred }}=0.9964$, $\mathrm{R}_{\text {Adj }}$ and $\mathrm{R}_{\text {Pred }}$ are close. The measurement signal-to-noise ratio is required to be greater than 4 , which is 194.653 . It shows that was an accurate model, which can be used to guide the following design.

In conclusion, according to the fitting analysis of the regression equation, the fitting degree between the independent variables and the response values is high. The regression effect is obvious. They were a good mathematical model for the subsequent optimal design of this sensor structure and can be used to guide the following selection of sensor parameters.

\section{Selection of final size parameters of elastomer}

The purpose of this paper is to ensure that the sensor have better sensitivity under the condition of high dynamic performance. Based on the response surface model, the key parameters of the sensor elastomer obtained by response surface analysis are showed in Table 2 . We can know from the analysis: the novel six-dimensional force sensor has good static and dynamic performance. The first-order natural frequency is $3196.30 \mathrm{~Hz}$, and the strain of the force component through the response surface analysis was increased after analysis and calculations. In other words, the sensitivity of the sensor was increased, including the sensitivity of the force Fx increased by $26.09 \%$, the sensitivity of the force Fz increased by $11.59 \%$, the sensitivity of the torque $\mathrm{Mx}$ increased by $24.94 \%$, the sensitivity of the torque $\mathrm{Mz}$ increased by $19.84 \%$. What's more, to verify the performance of the sensor, we have fabricated a physical prototype of the sensor by the combination of discharge machining and traditional machining. And we have tested the natural frequency of the elastomer by the LMS Test lab, the test results are in accordance with the expectation. Preliminarily verified the feasibility of the sensor.

Table 2. Comparison of key parameters of sensor elastomer.

\begin{tabular}{cccc}
\hline Initial Model & $\begin{array}{l}\text { Terminal } \\
\text { Model }\end{array}$ & $\begin{array}{c}\text { Rate of } \\
\text { Change }\end{array}$ \\
\hline$x_{1}$ & $5.00 \mathrm{~mm}$ & $4.00 \mathrm{~mm}$ & -- \\
$x_{2}$ & $5.00 \mathrm{~mm}$ & $5.96 \mathrm{~mm}$ & -- \\
$x_{3}$ & $4.50 \mathrm{~mm}$ & $4.24 \mathrm{~mm}$ & --
\end{tabular}




\begin{tabular}{cccc}
$x_{4}$ & $0.70 \mathrm{~mm}$ & $0.57 \mathrm{~mm}$ & - \\
$x_{5}$ & $0.70 \mathrm{~mm}$ & $0.77 \mathrm{~mm}$ & - \\
$x_{6}$ & $0.70 \mathrm{~mm}$ & $0.63 \mathrm{~mm}$ & -- \\
$y_{1}$ & $6.95 \mathrm{E}-04$ & $1.75 \mathrm{E}-03$ & $+26.09 \%$ \\
$y_{2}$ & $1.66 \mathrm{E}-03$ & $1.85 \mathrm{E}-03$ & $+11.59 \%$ \\
$y_{3}$ & $3.43 \mathrm{E}-03$ & $4.28 \mathrm{E}-03$ & $+24.94 \%$ \\
$y_{4}$ & $2.02 \mathrm{E}-03$ & $2.42 \mathrm{E}-03$ & $+19.84 \%$ \\
$y_{5}$ & $3191.70 \mathrm{~Hz}$ & $3196.30 \mathrm{~Hz}$ & $+0.14 \%$ \\
\hline
\end{tabular}

\section{EXPERIMENT AND ANALYSIS}

The experimental platform of the six-dimensional force sensor is mainly composed of the sensor signal amplification module, signal acquisition module, PC equipped with serial debugging assistant, experimental bench of the six-dimensional force sensor and several weights, as shown in Figure 7.

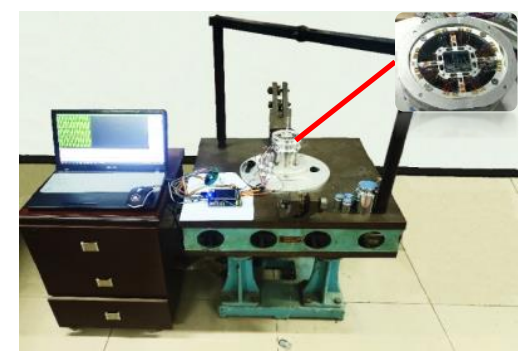

Figure 7. Experimental platform for six-dimensional force sensor.

The experimental bench of the six-dimensional force sensor is composed of a foundation support, a clamping device, a pulley block, a loading bar, a supporting bar and a number of steel wires. And it can carry out loading experiments of three-dimensional force and three-dimensional torque, static performance calibration experiments and dynamic measurement experiments of the sensor. The loading bar was designed to make the operating point of each load in the center of the sensor elastomer .

In the static loading experiment of the six-dimensional force sensor,firstly we should connect the sensor to the experimental bench through the clamping device, and rotate the clamping device to keep the sensor in a proper direction as the reference position. Then, passing the wire through the pulley block on the load bar. And make sure one end of the wire is connected to the loading bar on the sensor, and the other end is connected to the pre-prepared weight which is natural drooping. What is more, make sure weights do not swing or swing only slightly during the experiment. When loading different loads, it is only necessary to change the weight of different masses. After measuring several sets of data in one direction, adjusting the clamping device by $180^{\circ}$ or adjust the wire to other sets of pulley blocks for the measurement of the next set of experiments.

In this way, $\mathrm{Fx}, \mathrm{Mx}$, and $\mathrm{Mz}$ could be synthesized by appropriate horizontal forces $F_{1}, F_{2}$, and their distances $l_{1}$ and $l_{2}$ from the center of the elastomer. Fy was loaded in the same way as Fx, and My was loaded in the same way as Mx. The weight loading diagram of each working condition is shown in Figure 8.

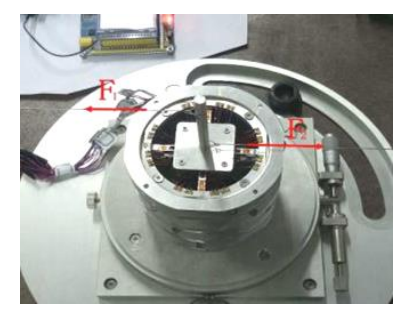

(a)

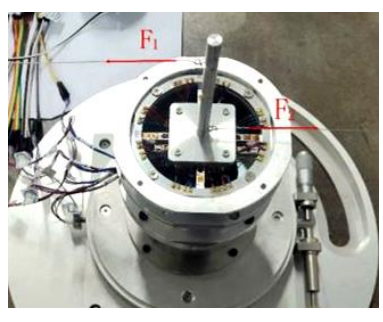

(b)

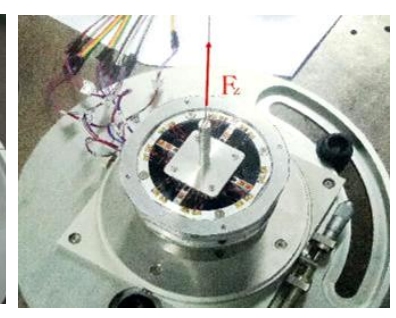

(b)

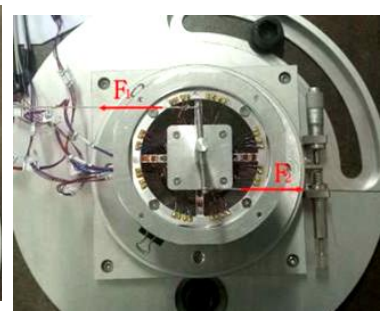

(c)
Figure 8. (a) Weight loading diagram of force $F_{x}$; (b) Weight loading diagram of force $F_{z}$; (c)Weight loading diagram of moment $M_{x}$; (b) Weight loading diagram of moment $M_{z}$.

After several loads, the average value of the output voltage is calculated. And the relationship curve between the load and the output voltage in each working condition is shown in the Figure 9. It is observed that the relationship between the load and the output voltage in each working condition is linear. 


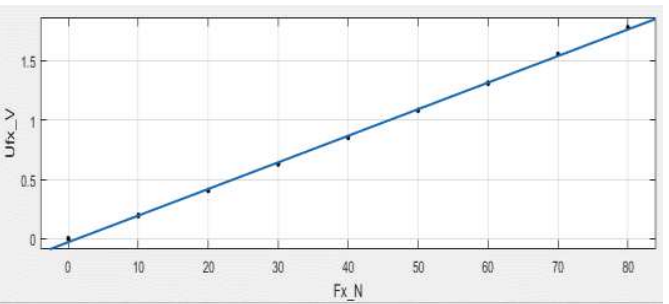

(a)

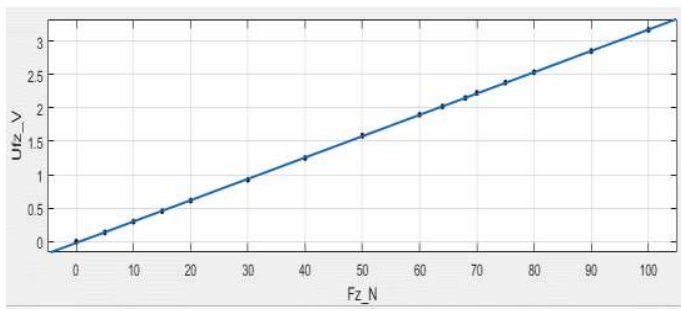

(b)

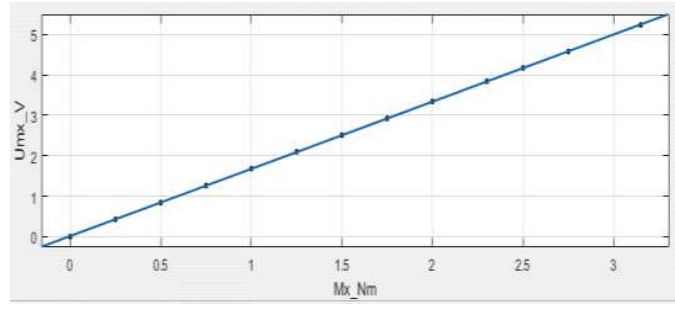

(c)

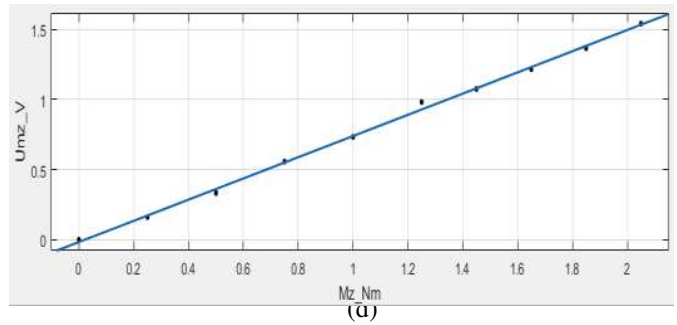

Figure 9. (a) Relationship between $F_{x}$ and output voltage $U_{F x}$; (b) Relationship between $F_{x}$ and output voltage $U_{F z}$; (c) Relationship between $M_{x}$ and output voltage $U_{M x}$; (d) Relationship between $M_{z}$ and output voltage $U_{M z}$.

In addition, according to the actual measurement data, we use the MATLAB to fit the mathematical relationship between the load under each working condition and the corresponding output voltage of the full bridge circuit as follows:
$\mathrm{U}_{\mathrm{Fx}}$

The correlation coefficient R2 of the mathematical model is 0.9994, and the correction coefficient $R_{a d j}^{2}$ is 0.9993, indicating that the fitting effect is good and close to the real mathematical model.

$$
\mathrm{U}_{\mathrm{Fy}}=(\mathrm{Fy} \times 2.1430-0.8064) \times 10-2 \mathrm{~V} / \mathrm{N}
$$

The correlation coefficient $\mathrm{R} 2$ of the mathematical model is 0.9999 , and the correction coefficient $R_{a d j}^{2}$ is 0.9999, indicating that the fitting effect is good and very close to the real mathematical model.

$$
\mathrm{U}_{\mathrm{Fz}}=(\mathrm{Fz} \times 3.1870-1.7020) \times 10-2 \mathrm{~V} / \mathrm{N}
$$

The correlation coefficient R2 of the mathematical model is 1 , and the correction coefficient $R_{a d j}^{2}$ is 0.9999 , indicating that the fitting effect is good and very close to the real mathematical model.

$$
\mathrm{U}_{\mathrm{Mx}}=\mathrm{Mx} \times 1.6620+1.5070 \times 10-2 \mathrm{~V} / \mathrm{N}
$$

The correlation coefficient R2 of the mathematical model is 1 , and the correction coefficient $R_{a d j}^{2}$ is 1 , indicating that the fitting effect is very good, and it completely conforms to the real mathematical model.

$$
\mathrm{U}_{\mathrm{My}}=\mathrm{My} \times 1.7340+5.2740 \times 10-3 \mathrm{~V} / \mathrm{N}
$$

The correlation coefficient R2 of the mathematical model is 0.9999 , and the correction coefficient $R_{a d j}^{2}$ is 0.9999, indicating that the fitting effect is good and very close to the real mathematical model.

$$
\mathrm{U}_{\mathrm{Mz}}=\mathrm{Mz} \times 0.7556+1.5910 \times 10-2 \mathrm{~V} / \mathrm{N}
$$

The correlation coefficient R2 of the mathematical model is 0.9981, and the correction coefficient $R_{a d j}^{2}$ is 0.9979 , indicating that the fitting effect is good and very close to the real mathematical model.

Theoretically, the relation between Fx and Fy and their output voltage should be the same, but the corresponding relation between them is different due to the paste position error of the strain gauge and the resistance error of the strain gauge itself. And the same goes for Mx and My.

\section{CONCLUSIONS}

(1) According to the novel sensor elastomer structure, the connection mode of wheatstone full bridge circuit is determined and the theoretical decoupling is realized. The response surface analysis method is utilized to fit the regression 
equation of the response values and the key size parameters of the elastomer under different working conditions. And we finished the design of the key size parameters of the elastomer, which not only ensures the sensor has certain dynamic performance but also improves the sensitivity of the sensor.

(2) To verify the performance of the sensor, the natural frequency of the elastomer was tested by the LMS Test lab. The test results were consistent with expectations. Also, through the detailed optimization design of the elastomer, the static and dynamic performance of the sensor need to be further improved to meet the requirements of the high-speed and high-precision robots.

(3)In order to verify the accuracy of the calculation and analysis results in this paper, the six-dimensional force sensor was verified experimentally. And the experimental results show that the linear relationship between the load and output voltage of the six-dimensional force sensor is consistent with the design expectation.

\section{PATENTS}

Yong Wang, Chunfeng Li, Shanshan $\mathrm{Hu}$, et al. A kind of six-dimensional force sensor. [P] CN109238528.

\section{FUNDING}

This work was supported by the National Natural Science Foundation of China (JZ2018GJLH0078).

\section{AVAILABILITY OF DATA AND MATERIALS}

The datasets used or analysed during the current study are available from the corresponding author on reasonable request.

\section{COMPETING INTERESTS}

The authors declare no conflict of interest.

\section{AUTHORS' CONTRIBUTIONS}

Conceptualization, C.Z., Y.W. and J.Z.; formal analysis, C.Z., C.L. and S.H.; funding acquisition, project administration, validation, Y.W. and J.Z.; writing - original draft preparation, C.Z.; writing - review and editing, C.Z., and C.L.

\section{ACKNOWLEDGEMENTS}

We would like to express my gratitude to all those who helped me during the writing of this thesis.

First of all, we have to thank the National Natural Scinece Foundation of China. Only with their support can we afford to do experimental research.
Secondly, we would like to thank Hefei University of Technology for training us and providing us with a good platform for learning and communication.

Finally, we would like to thank all the members of Professor Yong Wang's research group for their help in the experiment and paper revision.

\section{REFERENCES}

[1] Wang Zhijun, Wang Kai, Liu Xuanyou. Overview of decoupling of six dimensional force sensors $[\mathrm{J}]$. Mechanical engineering and automation, 2018, (2):220-221.

[2] Zhang Chen. Research status analysis of multi-dimensional force sensor [J]. Journal of north China University of Technology, 2017(2).

[3] Zhong Xiaoling, Zhang Xiaoxia. Overview of multi-dimensional force/torque sensors for robots [J]. Sensors and Microsystems, 2015, 34(5):1-4.

[4] Yuan C, Luo L P, Yuan Q, et al. Development and evaluation of a compact 6 axis force/moment sensor with a serial structure for the humanoid robot foot [J]. Measurement, 2015, 70: 110122.

[5] Yuan C, Xue G, Yang M Z, et al. Mathematical modeling of a six-axis force/moment sensor[C]//Control, Automation and Systems (ICCAS), 2015 15th International Conference on. IEEE, 2015: 1404-1409.

[6] Ge yu, liang qiaokang, song quanjun, et al. Ultra-thin six-dimensional force sensor and its method for measuring three-dimensional force and three-dimensional torque information [P]. CN101419102.

[7] Liang Q, Zhang D, Song Q, et al. Design and fabrication of a six -dimensional wrist force/torque sensor based on E-type membranes compared to cross beams [J]. Measurement, 2010, 43(10): 1702-1719.

[8] Xiong yaqing, yu weijian. Structural design and optimization of a new self-decoupling six-dimensional force/torque sensor [J]. Sensor and microsystem, 2015, (11):106-108.

[9] Ma, J.; Song, A. Fast Estimation of Strains for Cross-Beams Six-Axis Force/Torque Sensors by Mechanical Modeling. Sensors 2013, 13, 66696686.

[10] Wang Y.; Zuo, G.; Chen, X.; Liu, L. Strain Analysis of Six-Axis Force/Torque Sensors Based on Analytical Method. IEEE Sens. J. 2017, 17, 4394-4404.

[11] Kang, M.K.; Lee, S.; Kim, J.H. Shape optimization of a mechanically decoupled six-axis force/torque sensor. Sens. Actuators a 2014, 209, 4151 .

[12] Zhang qiang, song aiguo, liu yuqing, et al. Design of a fingertip 3d force sensor [J]. Journal of metrology, 2018, (1):52-55.

[13] Sun Y, Liu Y, Zou T, et al. Design and optimization of a novel six-axis force/torque sensor for space robot [J]. Measurement, 2015, 65:135-148.

[14] Shanshan Hu; Huaiyang Wang; Yong Wang; et al. Design of a Novel Six-Axis Wrist Force Sensor [J]. Sensors, 2018.18(9):1-17.

[15] A.I. Khuri, S. Mukhopadhyay, Response surface methodology, Wiley Interdiscipl. Rev.: Comput. Stat. 2 (2) 2010 128-149. 
[16] Ilhan. Asiltürk, Süleyman. Neseli, Multi response optimization of CNC turning parameters via Taguchi method-based response surface analysis, Measurement 45 (4) 2012 785-794.

[17] Thiagarajan Rajmohan, Kayaroganam Palanikumar, Application of the central composite design in optimization of machining parameters in drilling hybrid metal matrix composites, Measurement 46 (4) 20131470 1481 .

[18] Yang boyuan. Mechanics of materials [M]. China machinery industry press: Beijing, 2002.

[19] Xu, Z. A Brief Tutorial on Elastic Mechanics; Higher Education Press: Beijing, China, 2002.

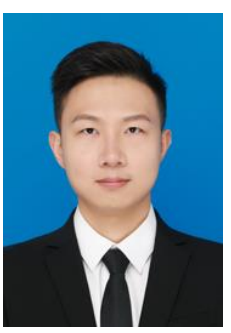

First A. Author received his B.S.degree from AhHui University of Technology (AFUT), Maanshan, China, in 2018. He is pursuing the M.A. degree at Hefei University of Technology (HFUT), Hefei, China. His research interests include force sensor, and signal processing.
Second B. Author is a professor of Hefei University of Technology (HFUT), Hefei, China. He received his B.S. and Ph.D. degrees from Hefei University of Technology (HFUT), Hefei, China, in 1990 and 2008. His research interests include the rehabilitation engineering, force sensor.

Third C. Author received his M.A. degree from Hefei University of Technology (HFUT), Hefei, China, in 2020.

Fourth D. Author received his Ph.D degree from Hefei University of Technology (HFUT), Hefei, China, in 2019.

Fifth E. Author is received his $\mathrm{PhD}$. degree in computer science from Hefei University of Technology in 2001. He is currently an associate professor of information management and information system at the School of Management, Hefei University of Technology, China.

His research interests include the modeling, simulation and optimization of logistic and supply chain systems, information resource management and intelligent manufacturing.

\section{APPENDIX}

Table 1. Response surfaces analysis table and numerical calculation results

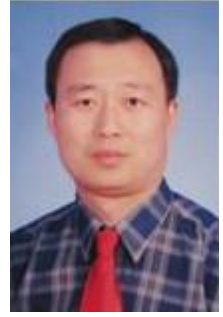

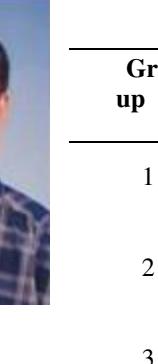

\begin{tabular}{|c|c|c|c|c|c|c|c|c|c|c|c|}
\hline $\begin{array}{l}\text { Gro } \\
\text { up }\end{array}$ & $x_{1}$ & $x_{2}$ & $x_{3}$ & $x_{4}$ & $x_{5}$ & $x_{6}$ & $y_{1}$ & $y_{2}$ & $y_{3}$ & $y_{4}$ & $y_{5}$ \\
\hline 1 & $00^{5 .}$ & $\begin{array}{c}6 . \\
00\end{array}$ & $\begin{array}{c}4 . \\
50\end{array}$ & 75 & $\begin{array}{c}0 . \\
50\end{array}$ & $\begin{array}{l}0.4 \\
0\end{array}$ & $\begin{array}{c}2.58 \mathrm{E}-0 \\
3\end{array}$ & $1.55 \mathrm{E}-03$ & $3.29 \mathrm{E}-03$ & $1.21 \mathrm{E}-03$ & $\begin{array}{c}3051.9 \\
0\end{array}$ \\
\hline 2 & $\begin{array}{l}4 . \\
00\end{array}$ & $\begin{array}{c}5 . \\
00\end{array}$ & $\begin{array}{c}4 . \\
50\end{array}$ & $\begin{array}{l}0 . \\
50\end{array}$ & 00 & $\begin{array}{l}0.6 \\
0\end{array}$ & $\begin{array}{c}1.78 \mathrm{E}-0 \\
3\end{array}$ & $3.57 \mathrm{E}-03$ & $8.47 \mathrm{E}-03$ & $1.46 \mathrm{E}-03$ & $\begin{array}{c}1923.0 \\
0\end{array}$ \\
\hline 3 & $\begin{array}{l}5 . \\
00\end{array}$ & $00^{6 .}$ & $\begin{array}{c}4 . \\
50\end{array}$ & 75 & 00 & $\begin{array}{l}0.8 \\
0\end{array}$ & $\begin{array}{c}1.10 \mathrm{E}-0 \\
3\end{array}$ & $1.47 \mathrm{E}-03$ & $3.32 \mathrm{E}-03$ & $1.18 \mathrm{E}-03$ & $\begin{array}{c}3006.6 \\
0\end{array}$ \\
\hline 4 & $\begin{array}{l}4 . \\
00\end{array}$ & $0^{5 .}$ & $\begin{array}{c}5 . \\
50\end{array}$ & 75 & $75^{0 .}$ & $\begin{array}{l}0.8 \\
0\end{array}$ & $\begin{array}{c}1.30 \mathrm{E}-0 \\
3\end{array}$ & $1.92 \mathrm{E}-03$ & $3.47 \mathrm{E}-03$ & $1.91 \mathrm{E}-03$ & $\begin{array}{c}2704.1 \\
0\end{array}$ \\
\hline 5 & 00 & 00 & 50 & 00 & 75 & $\begin{array}{l}0.8 \\
0\end{array}$ & $\begin{array}{c}1.19 \mathrm{E}-0 \\
3\end{array}$ & $1.04 \mathrm{E}-03$ & $1.11 \mathrm{E}-03$ & $1.72 \mathrm{E}-03$ & $\begin{array}{c}3546.2 \\
0\end{array}$ \\
\hline 6 & 00 & $\begin{array}{c}4 . \\
00\end{array}$ & $\begin{array}{c}4 . \\
50\end{array}$ & 75 & $\begin{array}{c}0 . \\
50\end{array}$ & $\begin{array}{l}0.8 \\
0\end{array}$ & $\begin{array}{c}1.27 \mathrm{E}-0 \\
3\end{array}$ & $1.56 \mathrm{E}-03$ & $1.82 \mathrm{E}-03$ & $3.89 \mathrm{E}-03$ & $\begin{array}{c}2868.6 \\
0\end{array}$ \\
\hline 7 & 00 & $\begin{array}{l}6 . \\
00\end{array}$ & 50 & 75 & 50. & $\begin{array}{l}0.6 \\
0\end{array}$ & $\begin{array}{c}1.69 \mathrm{E}-0 \\
3\end{array}$ & $1.55 \mathrm{E}-03$ & $3.33 \mathrm{E}-03$ & $2.57 \mathrm{E}-03$ & $\begin{array}{c}2982.4 \\
0\end{array}$ \\
\hline 8 & $\begin{array}{l}6 . \\
00\end{array}$ & 00 & $\begin{array}{c}4 . \\
50\end{array}$ & 00 & 00 & $\begin{array}{l}0.6 \\
0\end{array}$ & $\begin{array}{c}1.49 \mathrm{E}-0 \\
3\end{array}$ & $8.85 \mathrm{E}-04$ & 7.43E-04 & $1.12 \mathrm{E}-03$ & $\begin{array}{c}3866.5 \\
0\end{array}$ \\
\hline 9 & $\begin{array}{l}6 . \\
00\end{array}$ & $00^{5 .}$ & 50 & 75 & 75 & $\begin{array}{l}0.8 \\
0\end{array}$ & $\begin{array}{c}1.27 \mathrm{E}-0 \\
3\end{array}$ & $1.23 \mathrm{E}-03$ & $2.16 \mathrm{E}-03$ & $1.81 \mathrm{E}-03$ & $\begin{array}{c}3298.4 \\
0\end{array}$ \\
\hline 10 & 00 & $\begin{array}{l}4 . \\
00\end{array}$ & 50 & 75 & 00 & $\begin{array}{l}0.6 \\
0\end{array}$ & $\begin{array}{c}1.89 \mathrm{E}-0 \\
3\end{array}$ & $1.66 \mathrm{E}-03$ & $1.82 \mathrm{E}-03$ & $1.59 \mathrm{E}-03$ & $\begin{array}{c}2915.1 \\
0\end{array}$ \\
\hline 11 & $\begin{array}{l}5 . \\
00\end{array}$ & $\begin{array}{c}5 . \\
00\end{array}$ & $\begin{array}{c}5 . \\
50\end{array}$ & 00 & 75 & $\begin{array}{l}0.4 \\
0\end{array}$ & $\begin{array}{c}2.03 \mathrm{E}-0 \\
3\end{array}$ & $1.08 \mathrm{E}-03$ & $8.41 \mathrm{E}-04$ & $1.58 \mathrm{E}-03$ & $\begin{array}{c}3517.5 \\
0\end{array}$ \\
\hline
\end{tabular}




\begin{tabular}{|c|c|c|c|c|c|c|c|c|c|c|c|}
\hline 12 & 00 & 00 & $\begin{array}{l}4 . \\
50\end{array}$ & 00 & $\begin{array}{c}0 . \\
50\end{array}$ & $\begin{array}{l}0.6 \\
0\end{array}$ & $\begin{array}{l}2.01 \mathrm{E}-0 \\
3\end{array}$ & $1.31 \mathrm{E}-03$ & $1.39 \mathrm{E}-03$ & $2.95 \mathrm{E}-03$ & $\begin{array}{l}3341.1 \\
0\end{array}$ \\
\hline 13 & $\begin{array}{l}6 . \\
00\end{array}$ & 00 & 50 & $\begin{array}{l}0 . \\
50\end{array}$ & 50. & $\begin{array}{l}0.6 \\
0\end{array}$ & $\begin{array}{l}1.94 \mathrm{E}-0 \\
3\end{array}$ & $2.39 \mathrm{E}-03$ & 4.93E-03 & $3.02 \mathrm{E}-03$ & $\begin{array}{c}2306.9 \\
0\end{array}$ \\
\hline 14 & $\begin{array}{l}6 . \\
00\end{array}$ & 00 & 50 & 00 & 75 & $\begin{array}{l}0.6 \\
0\end{array}$ & $\begin{array}{l}1.71 \mathrm{E}-0 \\
3\end{array}$ & $9.92 \mathrm{E}-04$ & $9.42 \mathrm{E}-05$ & $2.07 \mathrm{E}-03$ & $\begin{array}{c}3464.8 \\
0\end{array}$ \\
\hline 15 & $\begin{array}{l}4 . \\
00\end{array}$ & 00. & $\begin{array}{l}4 . \\
50\end{array}$ & $\begin{array}{l}0 . \\
50\end{array}$ & $75^{0 .}$ & $\begin{array}{l}0.6 \\
0\end{array}$ & $\begin{array}{l}1.90 \mathrm{E}-0 \\
3\end{array}$ & $3.33 \mathrm{E}-03$ & $9.09 \mathrm{E}-03$ & $1.82 \mathrm{E}-03$ & $\begin{array}{c}1879.6 \\
0\end{array}$ \\
\hline 16 & $\begin{array}{l}6 . \\
00\end{array}$ & 00. & 50 & 75 & $75^{0 .}$ & $\begin{array}{l}0.8 \\
0\end{array}$ & $\begin{array}{l}1.21 \mathrm{E}-0 \\
3\end{array}$ & $1.28 \mathrm{E}-03$ & $2.14 \mathrm{E}-03$ & $1.68 \mathrm{E}-03$ & $\begin{array}{l}3136.8 \\
0\end{array}$ \\
\hline 17 & 00 & 00 & 50 & $\begin{array}{l}0 . \\
50\end{array}$ & 75 & $\begin{array}{l}0.8 \\
0\end{array}$ & $\begin{array}{l}1.27 \mathrm{E}-0 \\
3\end{array}$ & $2.85 \mathrm{E}-03$ & $5.96 \mathrm{E}-03$ & $1.67 \mathrm{E}-03$ & $\begin{array}{l}2082.1 \\
0\end{array}$ \\
\hline 18 & 00 & 00. & $\begin{array}{l}4 . \\
50\end{array}$ & 75 & 00 & $\begin{array}{l}0.8 \\
0\end{array}$ & $\begin{array}{l}1.30 \mathrm{E}-0 \\
3\end{array}$ & $1.56 \mathrm{E}-03$ & $1.86 \mathrm{E}-03$ & $1.63 \mathrm{E}-03$ & $\begin{array}{c}2881.2 \\
0\end{array}$ \\
\hline 19 & 00 & $00^{5 .}$ & $\begin{array}{l}3 . \\
50\end{array}$ & $\begin{array}{l}0 . \\
50\end{array}$ & $75^{0 .}$ & $\begin{array}{l}0.8 \\
0\end{array}$ & $\begin{array}{l}1.35 \mathrm{E}-0 \\
3\end{array}$ & $2.85 \mathrm{E}-03$ & $6.27 \mathrm{E}-03$ & $1.80 \mathrm{E}-03$ & $\begin{array}{c}2156.9 \\
0\end{array}$ \\
\hline 20 & 00 & 00. & 50 & 75 & 00 & $\begin{array}{l}0.6 \\
0\end{array}$ & $\begin{array}{l}1.41 \mathrm{E}-0 \\
3\end{array}$ & $1.57 \mathrm{E}-03$ & $3.00 \mathrm{E}-03$ & $1.06 \mathrm{E}-03$ & $\begin{array}{c}2979.2 \\
0\end{array}$ \\
\hline 21 & 00. & 00. & 50 & 00 & 50 & $\begin{array}{l}0.6 \\
0\end{array}$ & $\begin{array}{l}1.91 \mathrm{E}-0 \\
3\end{array}$ & 8.64E-04 & $9.53 \mathrm{E}-04$ & $3.03 \mathrm{E}-03$ & $\begin{array}{l}3762.5 \\
0\end{array}$ \\
\hline 22 & 00. & 00. & $\begin{array}{l}4 . \\
50\end{array}$ & 50 & 75 & $\begin{array}{l}0.6 \\
0\end{array}$ & $\begin{array}{c}1.66 \mathrm{E}-0 \\
3\end{array}$ & $2.22 \mathrm{E}-03$ & $4.88 \mathrm{E}-03$ & $1.43 \mathrm{E}-03$ & $\begin{array}{l}2260.2 \\
0\end{array}$ \\
\hline 23 & 00 & 00. & $\begin{array}{l}4 . \\
50\end{array}$ & 75 & 00 & $\begin{array}{l}0.4 \\
0\end{array}$ & $\begin{array}{l}1.93 \mathrm{E}-0 \\
3\end{array}$ & $1.57 \mathrm{E}-03$ & $3.06 \mathrm{E}-03$ & $1.12 \mathrm{E}-03$ & $\begin{array}{l}3050.1 \\
0\end{array}$ \\
\hline 24 & 00 & 00. & 50 & $\begin{array}{c}0 . \\
50\end{array}$ & 75 & $\begin{array}{l}0.4 \\
0\end{array}$ & $\begin{array}{l}2.23 \mathrm{E}-0 \\
3\end{array}$ & $2.90 \mathrm{E}-03$ & $5.82 \mathrm{E}-03$ & $1.77 \mathrm{E}-03$ & $\begin{array}{c}2121.4 \\
0\end{array}$ \\
\hline 25 & 00 & 00. & $\begin{array}{l}4 . \\
50\end{array}$ & 00 & 00 & $\begin{array}{l}0.6 \\
0\end{array}$ & $\begin{array}{l}1.79 \mathrm{E}-0 \\
3\end{array}$ & $1.32 \mathrm{E}-03$ & $1.64 \mathrm{E}-03$ & $1.58 \mathrm{E}-03$ & $\begin{array}{l}3351.2 \\
0\end{array}$ \\
\hline 26 & 00 & $00^{5 .}$ & $\begin{array}{l}4 . \\
50\end{array}$ & 75 & 75 & $\begin{array}{l}0.6 \\
0\end{array}$ & $\begin{array}{c}1.75 \mathrm{E}-0 \\
3\end{array}$ & $1.51 \mathrm{E}-03$ & $2.59 \mathrm{E}-03$ & $1.71 \mathrm{E}-03$ & $\begin{array}{l}3007.8 \\
0\end{array}$ \\
\hline 27 & 00 & $00^{5 .}$ & $\begin{array}{c}4 . \\
50\end{array}$ & 75 & $75^{0 .}$ & $\begin{array}{l}0.6 \\
0\end{array}$ & $\begin{array}{l}1.75 \mathrm{E}-0 \\
3\end{array}$ & $1.51 \mathrm{E}-03$ & $2.59 \mathrm{E}-03$ & $1.71 \mathrm{E}-03$ & $\begin{array}{l}3007.8 \\
0\end{array}$ \\
\hline 28 & 00 & 00 & 50 & 75 & 75 & $\begin{array}{l}0.4 \\
0\end{array}$ & $\begin{array}{l}3.08 \mathrm{E}-0 \\
3\end{array}$ & $1.93 \mathrm{E}-03$ & $3.41 \mathrm{E}-03$ & $2.04 \mathrm{E}-03$ & $\begin{array}{l}2798.8 \\
0\end{array}$ \\
\hline 29 & 00 & 00 & 50 & 75 & 75 & $\begin{array}{l}0.6 \\
0\end{array}$ & $\begin{array}{l}1.75 \mathrm{E}-0 \\
3\end{array}$ & $1.53 \mathrm{E}-03$ & $2.59 \mathrm{E}-03$ & $1.71 \mathrm{E}-03$ & $\begin{array}{l}3007.7 \\
0\end{array}$ \\
\hline 30 & 00 & 00 & 50 & 75 & 00 & $\begin{array}{l}0.6 \\
0\end{array}$ & $\begin{array}{l}1.49 \mathrm{E}-0 \\
3\end{array}$ & $1.66 \mathrm{E}-03$ & $1.79 \mathrm{E}-03$ & $1.54 \mathrm{E}-03$ & $\begin{array}{l}2812.7 \\
0\end{array}$ \\
\hline 31 & $\begin{array}{l}6 . \\
00\end{array}$ & 00 & $\begin{array}{c}4 . \\
50\end{array}$ & $\begin{array}{l}0 . \\
50\end{array}$ & 00 & $\begin{array}{l}0.6 \\
0\end{array}$ & $\begin{array}{l}1.59 \mathrm{E}-0 \\
3\end{array}$ & $2.42 \mathrm{E}-03$ & 5.33E-03 & $1.16 \mathrm{E}-03$ & $\begin{array}{l}2290.5 \\
0\end{array}$ \\
\hline 32 & 00 & 00 & 50 & 00 & $75^{0 .}$ & $\begin{array}{l}0.6 \\
0\end{array}$ & $\begin{array}{l}1.91 \mathrm{E}-0 \\
3\end{array}$ & $1.48 \mathrm{E}-03$ & $6.39 \mathrm{E}-04$ & $2.41 \mathrm{E}-03$ & $\begin{array}{l}3063.2 \\
0\end{array}$ \\
\hline 33 & 00 & 00 & $\begin{array}{l}3 . \\
50\end{array}$ & 75 & $\begin{array}{l}0 . \\
50\end{array}$ & $\begin{array}{l}0.6 \\
0\end{array}$ & $\begin{array}{l}2.06 \mathrm{E}-0 \\
3\end{array}$ & $1.50 \mathrm{E}-03$ & 3.33E-03 & 2.77E-03 & $\begin{array}{l}3102.0 \\
0\end{array}$ \\
\hline 34 & 00 & 00 & $\begin{array}{l}4 . \\
50\end{array}$ & 00 & $75^{0 .}$ & $\begin{array}{l}0.6 \\
0\end{array}$ & $\begin{array}{l}1.58 \mathrm{E}-0 \\
3\end{array}$ & $8.38 \mathrm{E}-04$ & $1.22 \mathrm{E}-03$ & $1.48 \mathrm{E}-03$ & $\begin{array}{l}4043.2 \\
0\end{array}$ \\
\hline 35 & 00 & $00^{5 .}$ & $\begin{array}{c}3 . \\
50\end{array}$ & 00 & 75 & $\begin{array}{l}0.8 \\
0\end{array}$ & $\begin{array}{l}1.31 \mathrm{E}-0 \\
3\end{array}$ & $1.03 \mathrm{E}-03$ & $1.25 \mathrm{E}-03$ & $1.78 \mathrm{E}-03$ & $\begin{array}{l}3735.1 \\
0\end{array}$ \\
\hline 36 & 00 & $00^{5 .}$ & 50 & 75 & 75 & $\begin{array}{l}0.4 \\
0\end{array}$ & $\begin{array}{l}2.36 \mathrm{E}-0 \\
3\end{array}$ & $1.92 \mathrm{E}-03$ & $3.42 \mathrm{E}-03$ & $1.89 \mathrm{E}-03$ & $\begin{array}{l}2721.6 \\
0\end{array}$ \\
\hline
\end{tabular}




\begin{tabular}{|c|c|c|c|c|c|c|c|c|c|c|c|}
\hline 37 & 00 & $\begin{array}{c}5 . \\
00\end{array}$ & 50 & 75 & 75 & $\begin{array}{l}0.8 \\
0\end{array}$ & $\begin{array}{c}1.42 \mathrm{E}-0 \\
3\end{array}$ & $1.86 \mathrm{E}-03$ & $3.82 \mathrm{E}-03$ & $2.14 \mathrm{E}-03$ & $\begin{array}{c}2807.8 \\
0\end{array}$ \\
\hline 38 & $00^{4 .}$ & $\begin{array}{c}5 . \\
00\end{array}$ & $\begin{array}{c}4 . \\
50\end{array}$ & $\begin{array}{l}0 . \\
50\end{array}$ & $\begin{array}{c}0 . \\
50\end{array}$ & $\begin{array}{l}0.6 \\
0\end{array}$ & $\begin{array}{c}2.06 \mathrm{E}-0 \\
3\end{array}$ & $3.29 \mathrm{E}-03$ & 8.03E-03 & $2.99 \mathrm{E}-03$ & $\begin{array}{c}1940.8 \\
0\end{array}$ \\
\hline 39 & 00 & $\begin{array}{c}5 . \\
00\end{array}$ & $\begin{array}{c}4 . \\
50\end{array}$ & 75 & 75 & $\begin{array}{l}0.6 \\
0\end{array}$ & $\begin{array}{c}1.75 \mathrm{E}-0 \\
3\end{array}$ & $1.55 \mathrm{E}-03$ & $2.59 \mathrm{E}-03$ & $1.71 \mathrm{E}-03$ & $\begin{array}{c}3007.8 \\
0\end{array}$ \\
\hline 40 & 00 & $\begin{array}{c}4 . \\
00\end{array}$ & $\begin{array}{l}3 . \\
50\end{array}$ & 75 & $\begin{array}{c}0 . \\
50\end{array}$ & $\begin{array}{l}0.6 \\
0\end{array}$ & $\begin{array}{c}2.18 \mathrm{E}-0 \\
3\end{array}$ & $1.65 \mathrm{E}-03$ & $1.67 \mathrm{E}-03$ & 4.05E-03 & $\begin{array}{c}2901.2 \\
0\end{array}$ \\
\hline 41 & 00 & $\begin{array}{c}4 . \\
00\end{array}$ & $\begin{array}{l}4 . \\
50\end{array}$ & $\begin{array}{l}0 . \\
50\end{array}$ & 75 & $\begin{array}{l}0.6 \\
0\end{array}$ & $\begin{array}{c}1.78 \mathrm{E}-0 \\
3\end{array}$ & $2.23 \mathrm{E}-03$ & 4.47E-03 & $2.18 \mathrm{E}-03$ & $\begin{array}{c}2297.8 \\
0\end{array}$ \\
\hline 42 & $00^{6 .}$ & $\begin{array}{c}5 . \\
00\end{array}$ & 50 & 75 & 75 & $\begin{array}{l}0.4 \\
0\end{array}$ & $\begin{array}{c}2.02 \mathrm{E}-0 \\
3\end{array}$ & $1.29 \mathrm{E}-03$ & $1.90 \mathrm{E}-03$ & $1.67 \mathrm{E}-03$ & $\begin{array}{c}3134.7 \\
0\end{array}$ \\
\hline 43 & 00 & $\begin{array}{c}6 . \\
00\end{array}$ & $\begin{array}{l}3 . \\
50\end{array}$ & 75 & 00 & $\begin{array}{l}0.6 \\
0\end{array}$ & $\begin{array}{c}1.81 \mathrm{E}-0 \\
3\end{array}$ & $1.51 \mathrm{E}-03$ & $3.21 \mathrm{E}-03$ & $1.23 \mathrm{E}-03$ & $\begin{array}{c}3093.2 \\
0\end{array}$ \\
\hline 44 & 00 & $00^{5 .}$ & 50 & 00 & $75^{0 .}$ & $\begin{array}{l}0.4 \\
0\end{array}$ & $\begin{array}{c}2.65 \mathrm{E}-0 \\
3\end{array}$ & $1.10 \mathrm{E}-03$ & 8.74E-04 & $1.73 \mathrm{E}-03$ & $\begin{array}{c}3679.7 \\
0\end{array}$ \\
\hline 45 & 00 & $\begin{array}{c}5 . \\
00\end{array}$ & $\begin{array}{c}4 . \\
50\end{array}$ & 75 & 75 & $\begin{array}{l}0.6 \\
0\end{array}$ & $\begin{array}{c}1.75 \mathrm{E}-0 \\
3\end{array}$ & $1.50 \mathrm{E}-03$ & $2.59 \mathrm{E}-03$ & $1.71 \mathrm{E}-03$ & $\begin{array}{c}3007.7 \\
0\end{array}$ \\
\hline 46 & 00 & $\begin{array}{c}4 . \\
00\end{array}$ & $\begin{array}{c}4 . \\
50\end{array}$ & 75 & $\begin{array}{c}0 . \\
50\end{array}$ & $\begin{array}{l}0.4 \\
0\end{array}$ & $\begin{array}{c}2.67 \mathrm{E}-0 \\
3\end{array}$ & $1.67 \mathrm{E}-03$ & $1.65 \mathrm{E}-03$ & $3.92 \mathrm{E}-03$ & $\begin{array}{c}2821.1 \\
0\end{array}$ \\
\hline 47 & 00 & $\begin{array}{c}6 . \\
00\end{array}$ & $\begin{array}{l}4 . \\
50\end{array}$ & 00 & 75 & $\begin{array}{l}0.6 \\
0\end{array}$ & $\begin{array}{c}1.78 \mathrm{E}-0 \\
3\end{array}$ & $1.26 \mathrm{E}-03$ & $2.14 \mathrm{E}-03$ & $1.77 \mathrm{E}-03$ & $\begin{array}{c}3488.1 \\
0\end{array}$ \\
\hline 48 & $\begin{array}{l}4 . \\
00\end{array}$ & $\begin{array}{c}4 . \\
00\end{array}$ & $\begin{array}{c}4 . \\
50\end{array}$ & $\begin{array}{l}0 . \\
50\end{array}$ & 75 & $\begin{array}{l}0.6 \\
0\end{array}$ & $\begin{array}{c}2.00 \mathrm{E}-0 \\
3\end{array}$ & $3.31 \mathrm{E}-03$ & 7.04E-03 & $2.50 \mathrm{E}-03$ & $\begin{array}{c}1950.2 \\
0\end{array}$ \\
\hline 49 & 00 & $\begin{array}{l}5 . \\
00\end{array}$ & $\begin{array}{c}4 . \\
50\end{array}$ & 75 & 75 & $\begin{array}{l}0.6 \\
0\end{array}$ & $\begin{array}{c}1.75 \mathrm{E}-0 \\
3\end{array}$ & $1.50 \mathrm{E}-03$ & $2.59 \mathrm{E}-03$ & $1.71 \mathrm{E}-03$ & $\begin{array}{c}3007.8 \\
0\end{array}$ \\
\hline 50 & 00 & $\begin{array}{c}5 . \\
00\end{array}$ & 50 & $\begin{array}{c}0 . \\
50\end{array}$ & 75 & $\begin{array}{l}0.4 \\
0\end{array}$ & $\begin{array}{c}2.90 \mathrm{E}-0 \\
3\end{array}$ & $2.78 \mathrm{E}-03$ & $6.13 \mathrm{E}-03$ & $1.77 \mathrm{E}-03$ & $\begin{array}{c}2173.8 \\
0\end{array}$ \\
\hline 51 & $00^{6 .}$ & $\begin{array}{l}5 . \\
00\end{array}$ & $\begin{array}{l}3 . \\
50\end{array}$ & 75 & 75 & $\begin{array}{l}0.4 \\
0\end{array}$ & $\begin{array}{c}2.00 \mathrm{E}-0 \\
3\end{array}$ & $1.28 \mathrm{E}-03$ & $2.00 \mathrm{E}-03$ & $1.81 \mathrm{E}-03$ & $\begin{array}{c}3273.3 \\
0\end{array}$ \\
\hline 52 & 00 & $\begin{array}{c}6 . \\
00\end{array}$ & $\begin{array}{c}4 . \\
50\end{array}$ & 75 & $\begin{array}{l}0 . \\
50\end{array}$ & $\begin{array}{l}0.8 \\
0\end{array}$ & $\begin{array}{c}1.40 \mathrm{E}-0 \\
3\end{array}$ & $1.48 \mathrm{E}-03$ & $3.24 \mathrm{E}-03$ & $2.66 \mathrm{E}-03$ & $\begin{array}{l}3020.6 \\
0\end{array}$ \\
\hline 53 & 00 & $\begin{array}{c}4 . \\
00\end{array}$ & $\begin{array}{c}4 . \\
50\end{array}$ & 75 & 00 & $\begin{array}{l}0.4 \\
0\end{array}$ & $\begin{array}{c}2.05 \mathrm{E}-0 \\
3\end{array}$ & $1.69 \mathrm{E}-03$ & $2.05 \mathrm{E}-03$ & $1.53 \mathrm{E}-03$ & $\begin{array}{c}2839.1 \\
0\end{array}$ \\
\hline 54 & 00 & $\begin{array}{c}4 . \\
00\end{array}$ & $\begin{array}{c}5 . \\
50\end{array}$ & 75 & $\begin{array}{c}0 . \\
50\end{array}$ & $\begin{array}{l}0.6 \\
0\end{array}$ & $\begin{array}{c}1.82 \mathrm{E}-0 \\
3\end{array}$ & $1.64 \mathrm{E}-03$ & $1.73 \mathrm{E}-03$ & $3.76 \mathrm{E}-03$ & $\begin{array}{c}2799.0 \\
0\end{array}$ \\
\hline
\end{tabular}




\section{Figures}

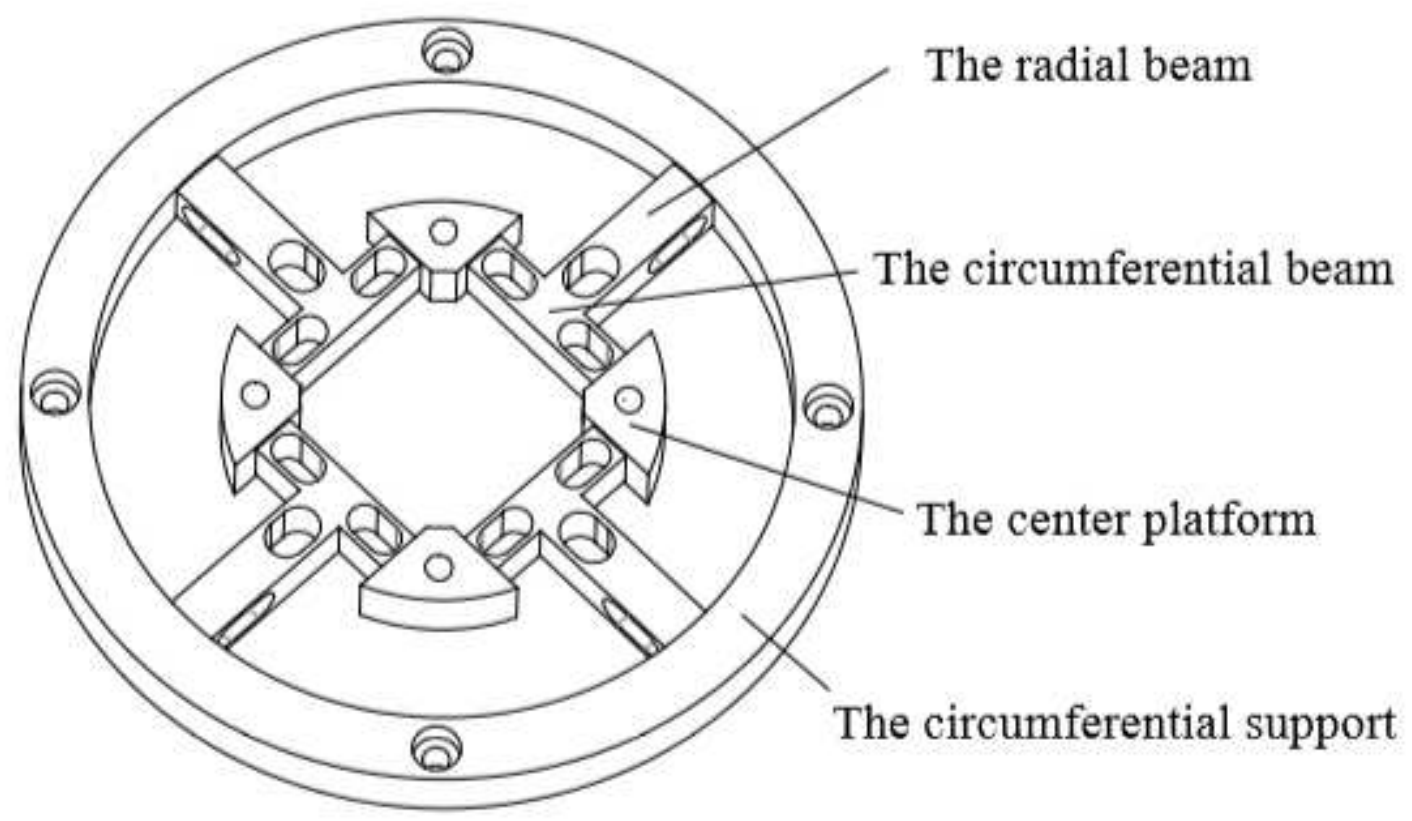

\section{Figure 1}

The elastic body of the novel cross beam six-dimensional force sensor.

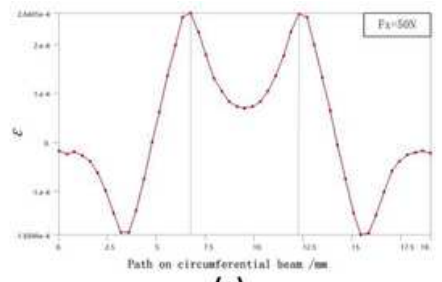

(a)

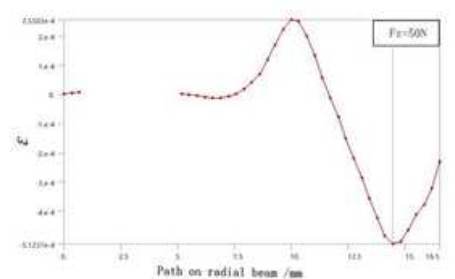

(b)

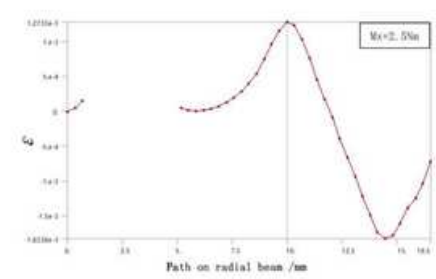

(c)

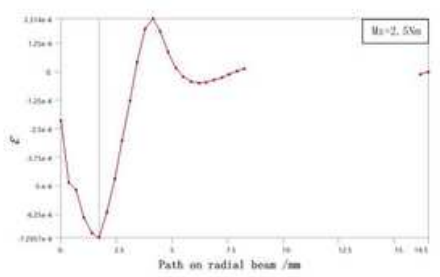

(d)

Figure 2

(a) Strain distribution along the path of the radial beam under $F x=50 N$; (b) Strain distribution along the path of the radial beam under $\mathrm{Fz}=50 \mathrm{~N}$; (c) Strain distribution along the path of the radial beam under $\mathrm{Mx}$ $=2.5 \mathrm{Nm}$; (d) Strain distribution along the path of radial beam under $\mathrm{Mz}=2.5 \mathrm{Nm}$. 


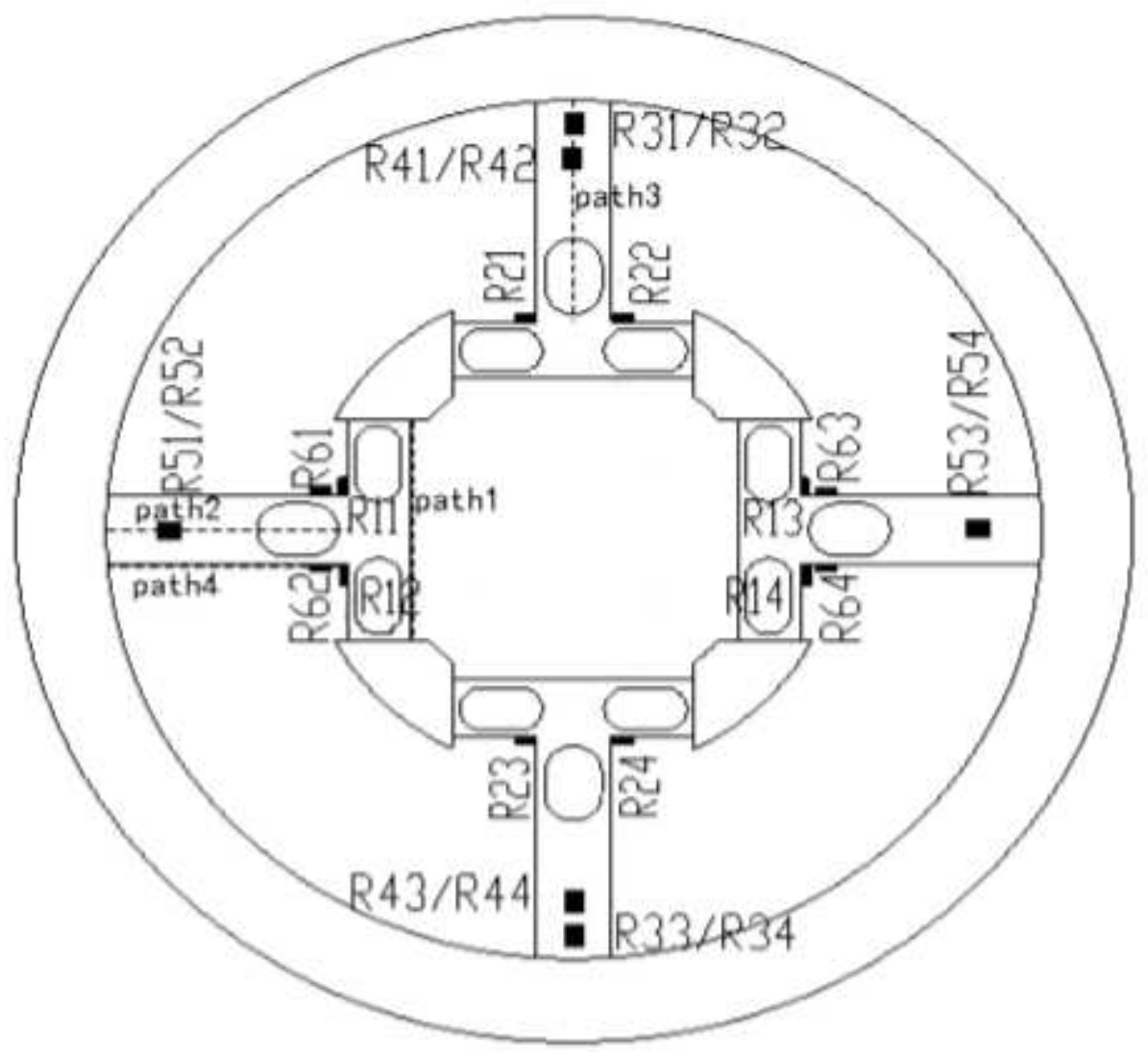

Figure 3

The strain gauges position of the novel six-dimensional force sensor.

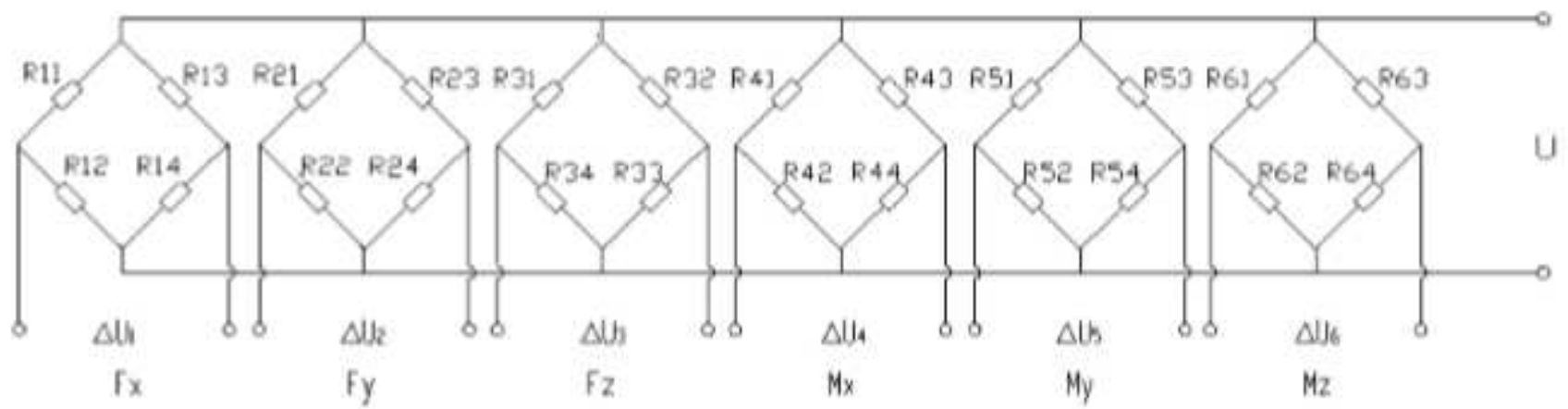

Figure 4

The Wheatstone full-bridge circuit connection mode. 


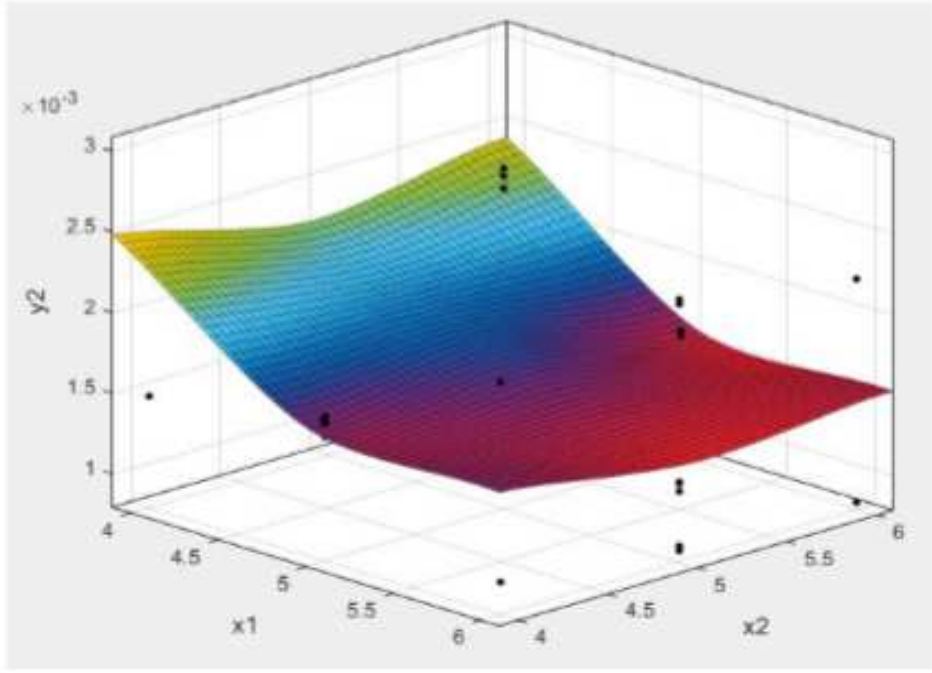

(a)

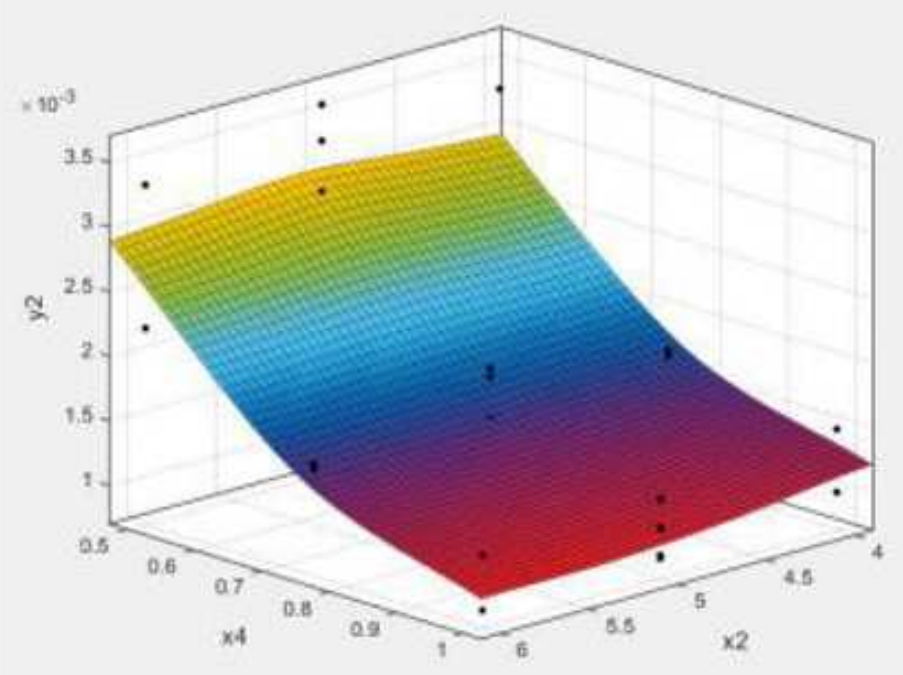

(c)

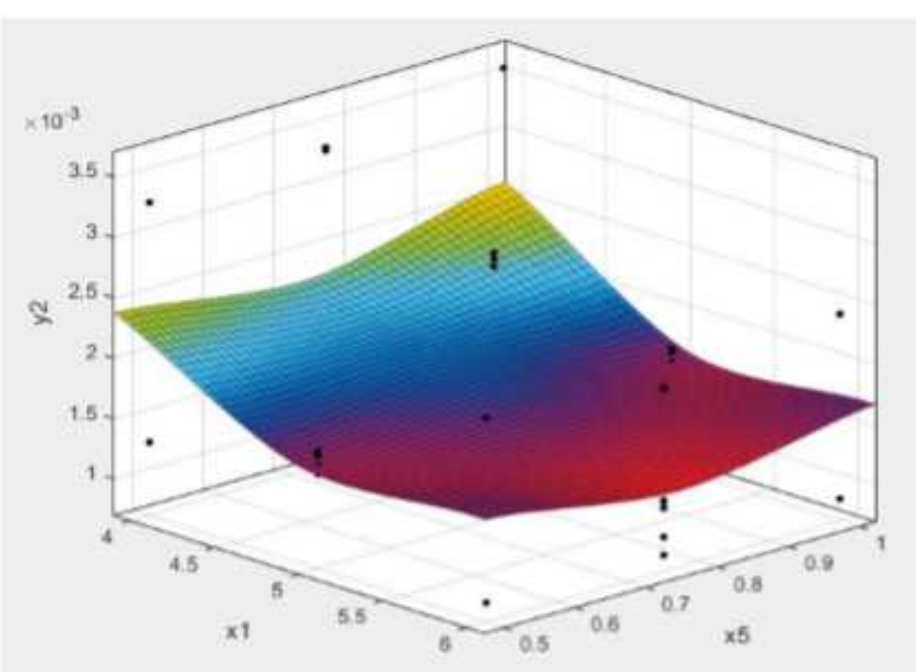

(b)

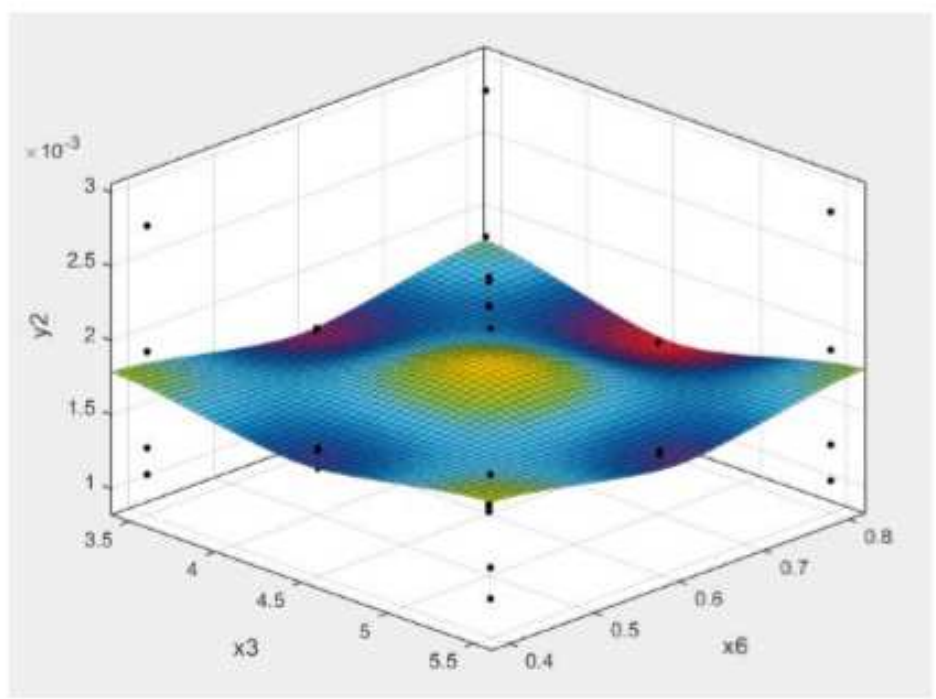

(d)

\section{Figure 5}

(a) Response surface of $y 2$ vs. $x 1, x 2$; (b) Response surface of y2 vs. $x 1, x 5$; (c) Response surface of y2 vs. $\times 2, \times 4$; (d) Response surface of $y 2$ vs. $\times 3, x 6$. 


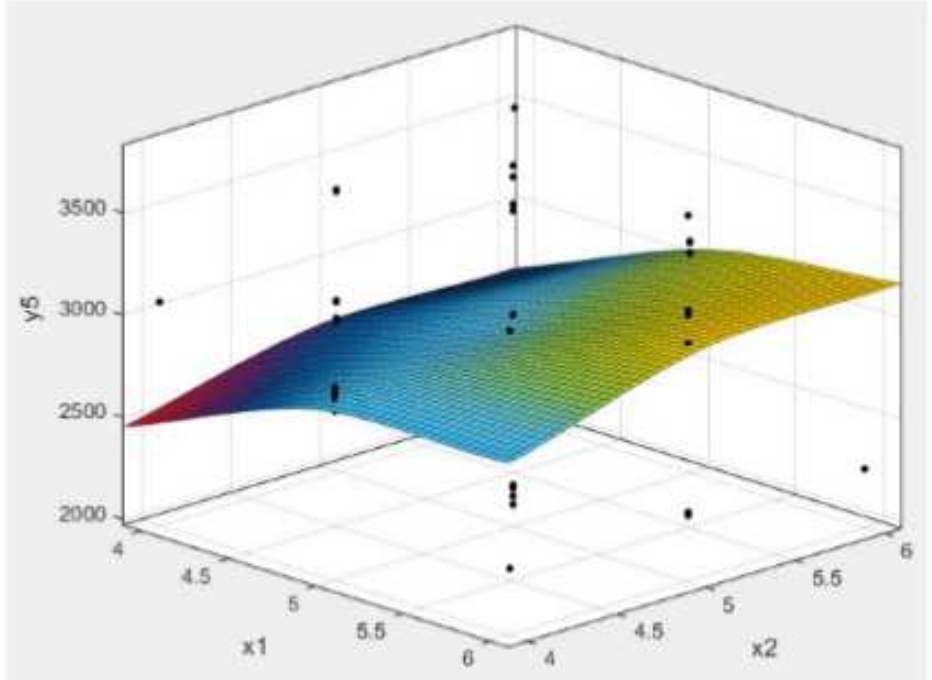

(a)

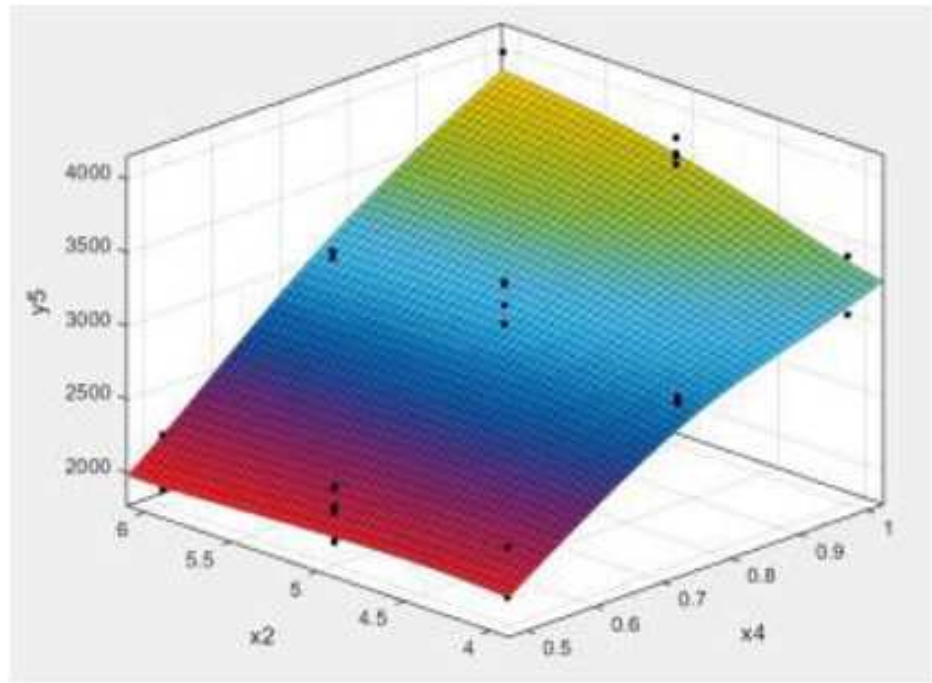

(c)

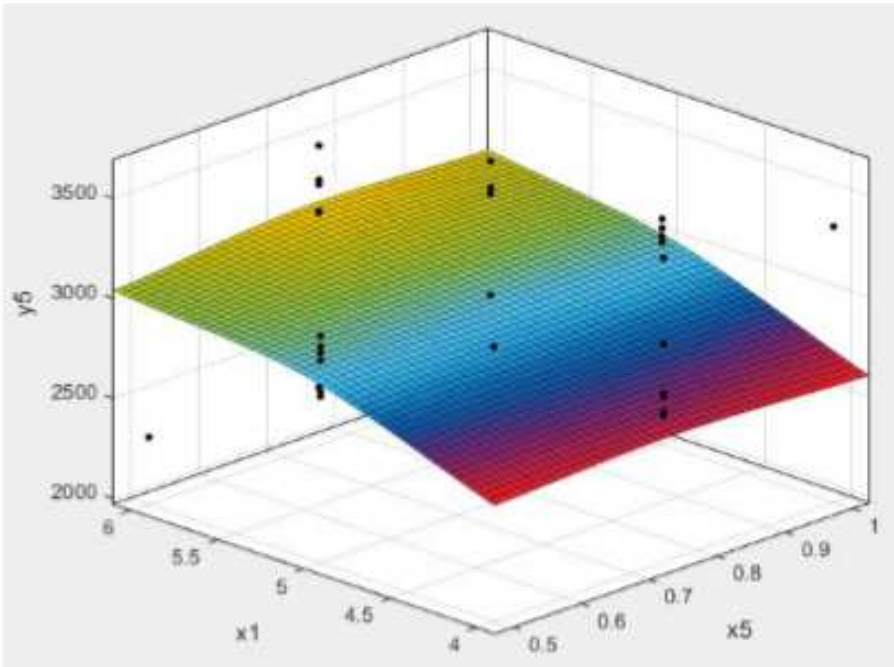

(b)

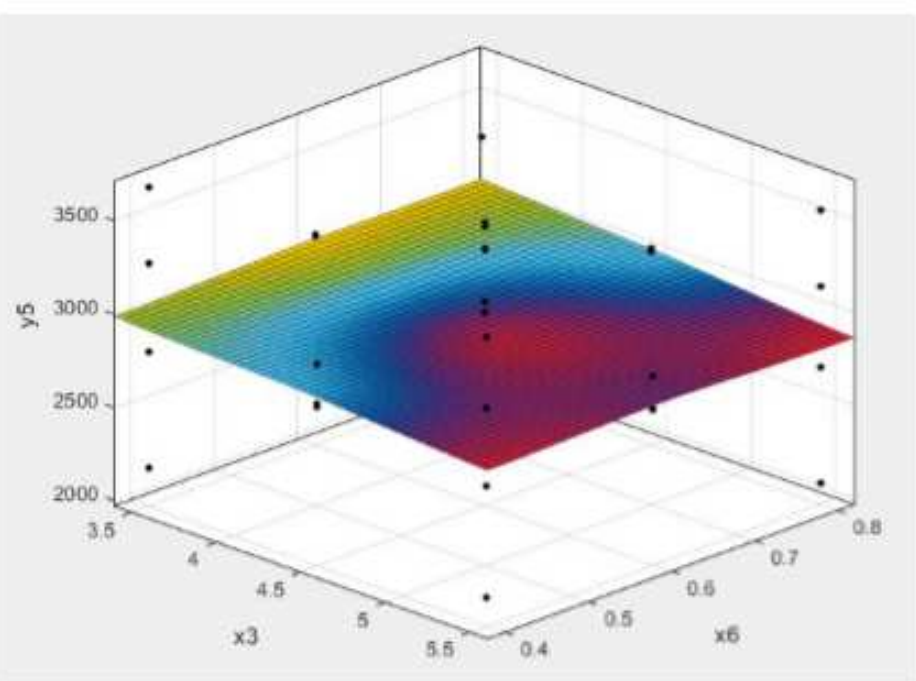

(d)

Figure 6

(a) Response surface of y5 vs. x1, x2; (b) Response surface of y5 vs. x1, x5; (c) Response surface of y5 vs. $x 2, x 4$; (d) Response surface of $y 5$ vs. $x 3, x 6$. 


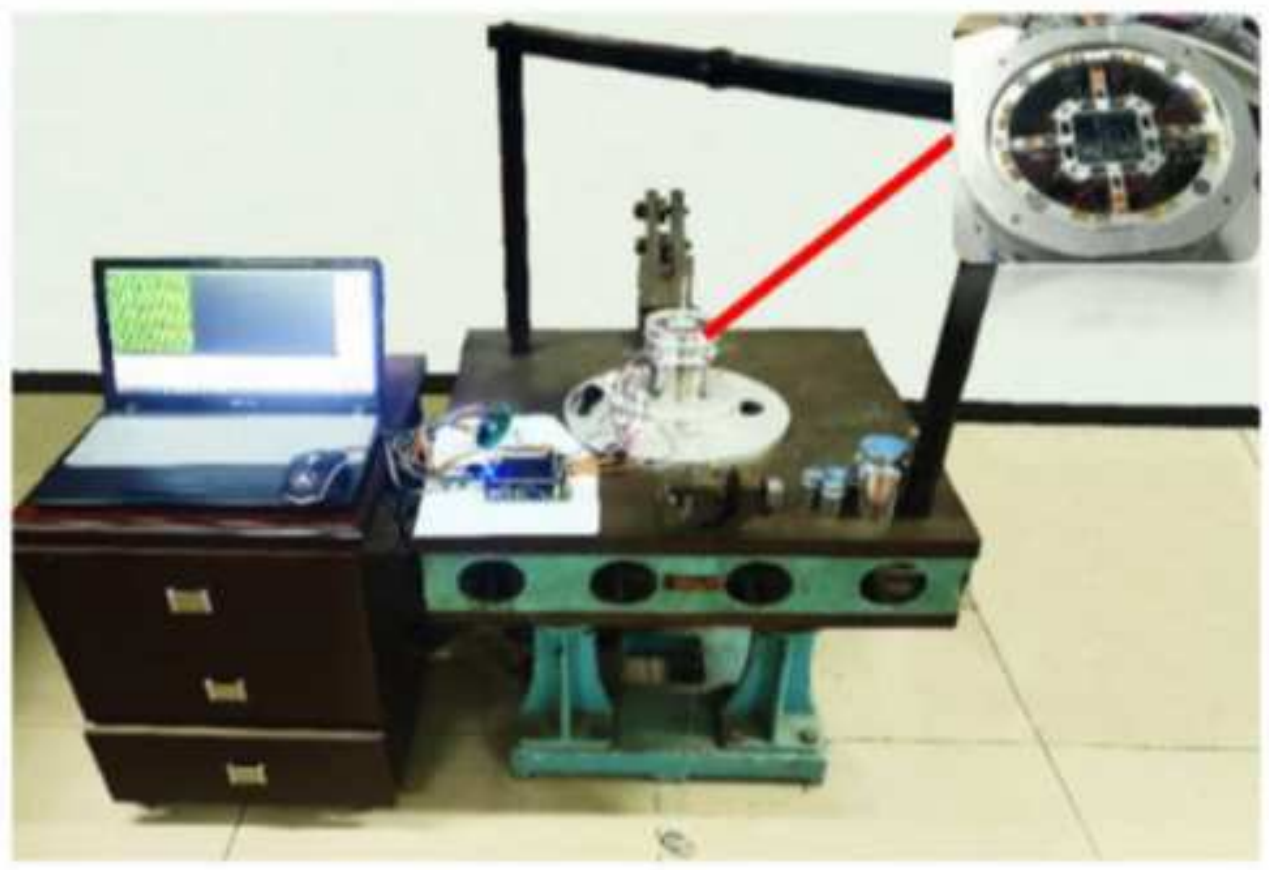

Figure 7

Experimental platform for six-dimensional force sensor. 


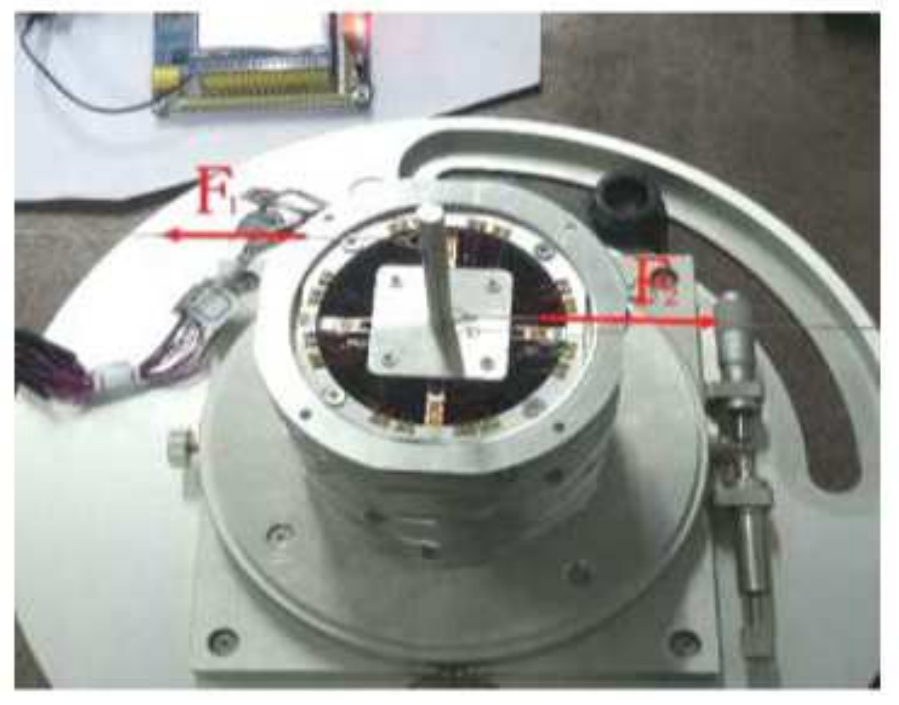

(a)

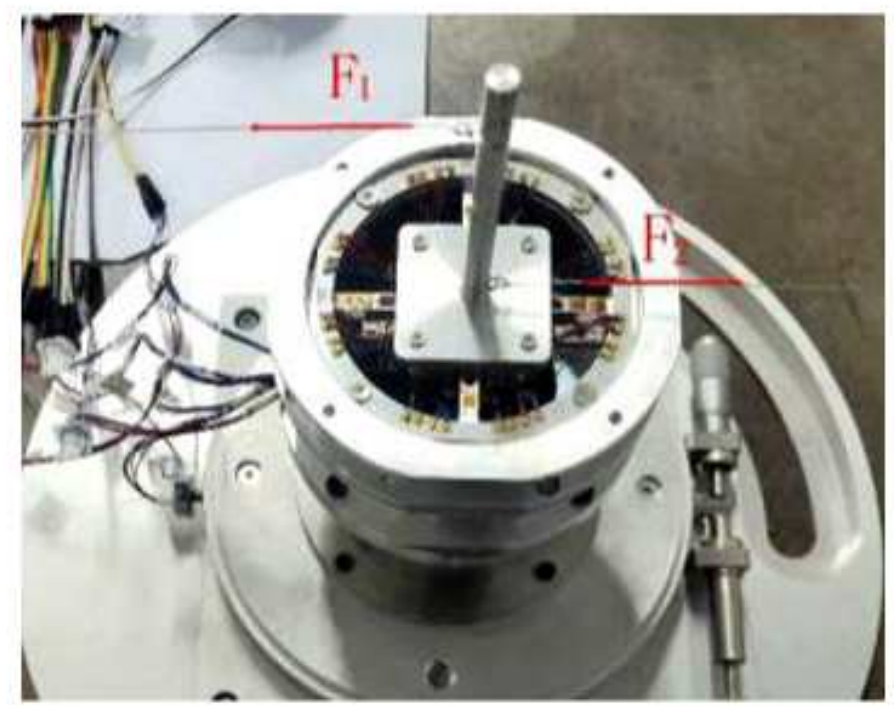

(b)

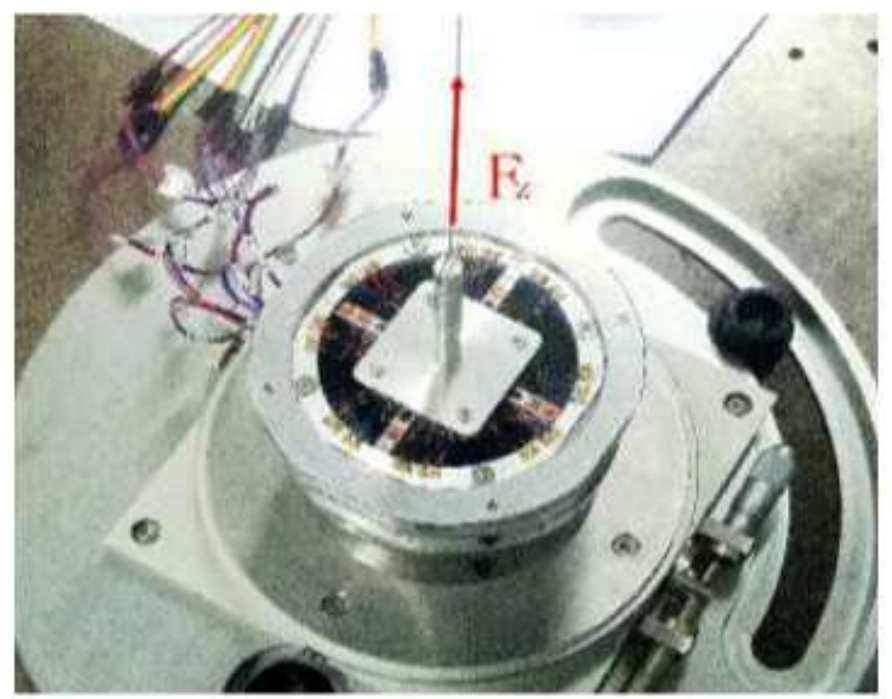

(b)

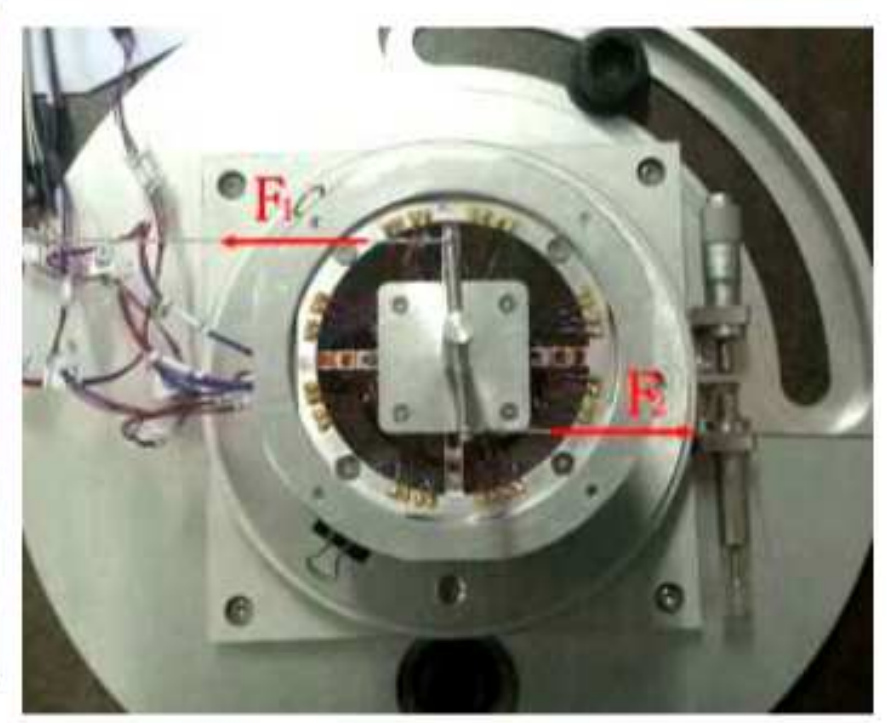

(c)

\section{Figure 8}

(a) Weight loading diagram of force Fx; (b) Weight loading diagram of force Fz; (c)Weight loading diagram of moment $\mathrm{Mx}$; (b) Weight loading diagram of moment $\mathrm{Mz}$. 


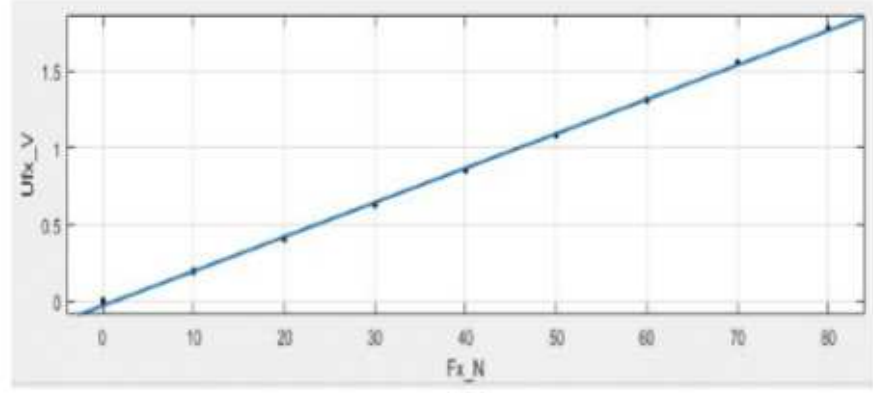

(a)

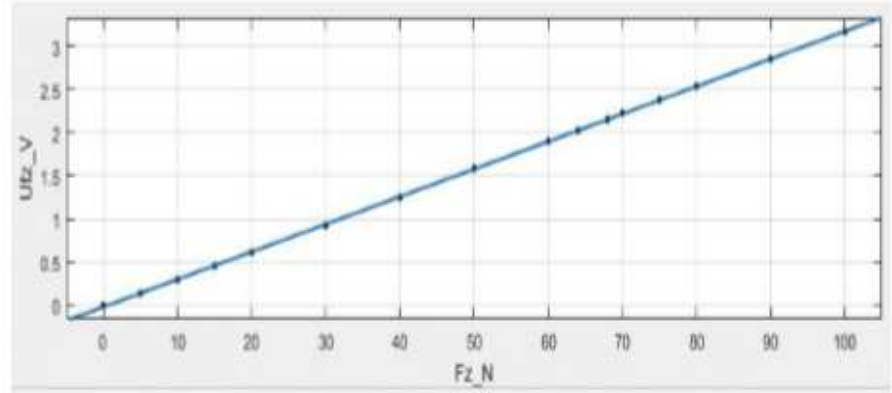

(b)

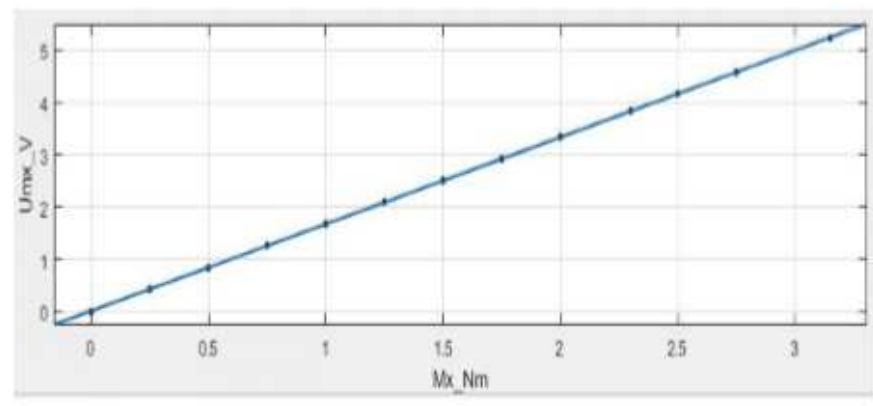

(c)

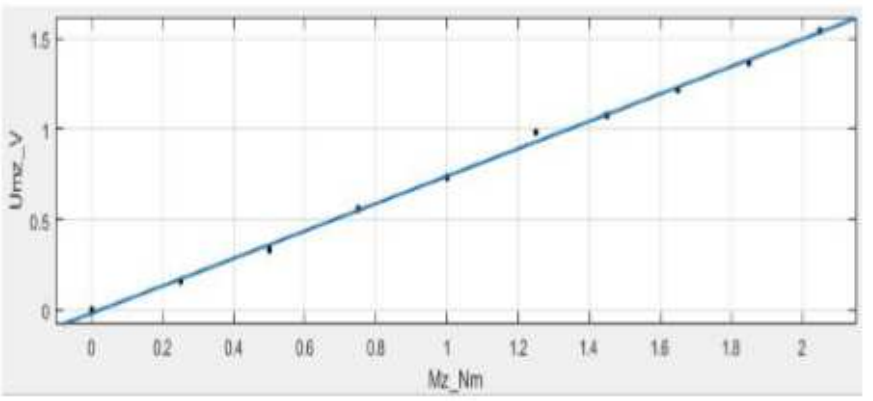

(d)

\section{Figure 9}

(a) Relationship between Fx and output voltage UFx; (b) Relationship between Fx and output voltage UFz; (c) Relationship between Mx and output voltage UMx; (d) Relationship between $\mathrm{Mz}$ and output voltage UMz. 